QA: N/A

BABFAH000-01717-0200-00121 REV 02

September 2001

\title{
Exploratory Studies Facility Subsurface Fire Hazards Analysis
}

By

J.L. Kubicek

Prepared for:

U.S. Department of Energy

Yucca Mountain Site Characterization

Office

P.O. Box 30307

North Las Vegas, Nevada 89036-0307

Prepared by:

Bechtel SAIC Company, LLC

1180 Town Center Drive

Las Vegas, Nevada 89144

Under Contract Number

DE-AC08-01RW12101 


\section{DISCLAIMER}

This report was prepared as an account of work sponsored by an agency of the United States Government. Neither the United States Government nor any agency thereof, nor any of their employees, nor any of their contractors, subcontractors or their employees, makes any warranty, express or implied, or assumes any legal liability or responsibility for the accuracy, completeness, or any third party's use or the results of such use of any information, apparatus, product, or process disclosed, or represents that its use would not infringe privately owned rights. Reference herein to any specific commercial product, process, or service by trade name, trademark, manufacturer, or otherwise, does not necessarily constitute or imply its endorsement, recommendation, or favoring by the United States Government or any agency thereof or its contractors or subcontractors. The views and opinions of authors expressed herein do not necessarily state or reflect those of the United States Government or any agency thereof. 
Exploratory Studies Facility Subsurface Fire Hazards Analysis

Prepared by:

bohu Kubicet

J.L. Kubicek

Fire Protection Engineer,

Subsurface Design Department

Checked by:

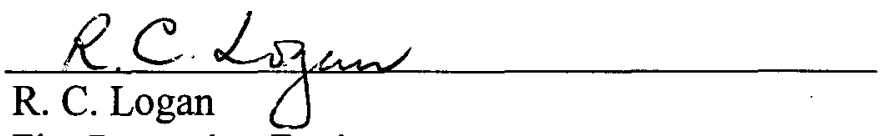

Fire Protection Engineer,

Subsurface Design Department

Approyed by:

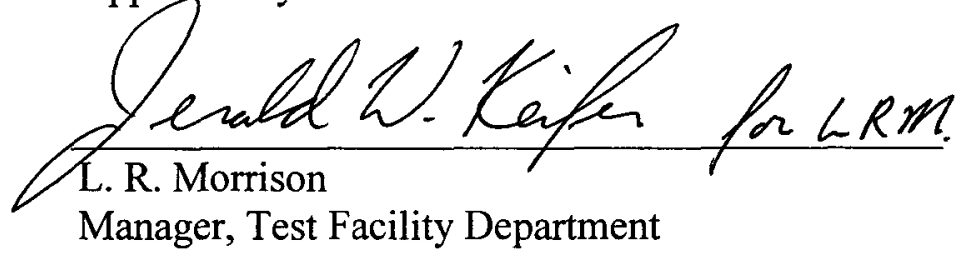

$\frac{09-07-01}{\text { Date }}$

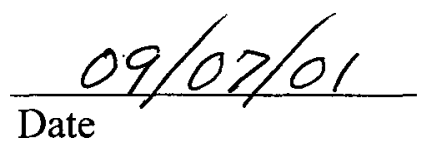




\section{CHANGE HISTORY}

$\begin{array}{lll}\text { Revision } & \text { Interim } & \text { Effective } \\ \text { Number } & \text { Change No. } & \text { Date }\end{array}$

00

01

$07 / 08 / 94$

$03 / 18 / 98$

\section{Description of Change}

Initial issue

Revised to incorporate a major update of the analysis to review current as-built conditions in the ESF, and to add the ECRB Cross-Drift construction activity. The whole analysis has been revised.

Removes TBD-137 and TBD-138

Removes TBV-196 and TBV-197

02
This revision incorporates a major format change to present the identified hazard discussion by separate section for clarification, and to include the results of a site walk down confirming the objectives of the FHA are being met. This revision includes a change of title (to clarify scope) from "Subsurface Fire Hazards Analysis" to "Exploratory Studies Facility Subsurface Fire Hazards Analysis." 


\section{CONTENTS}

Page

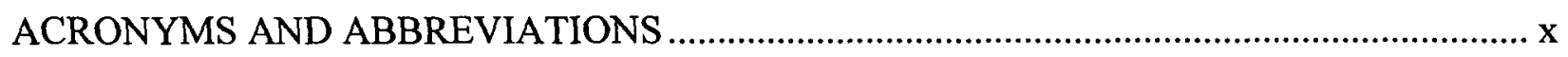

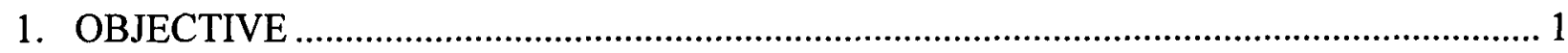

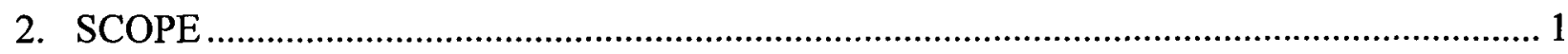

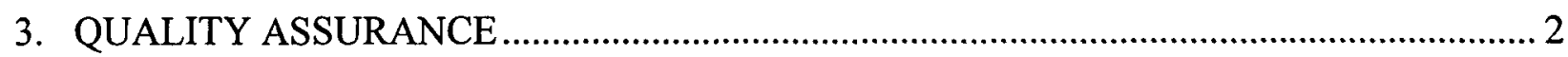

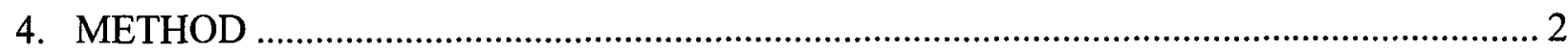

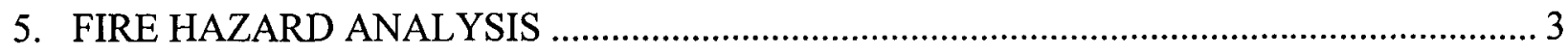

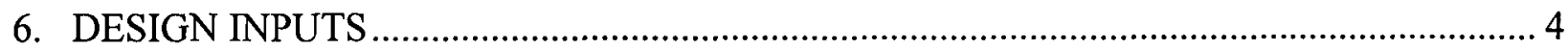

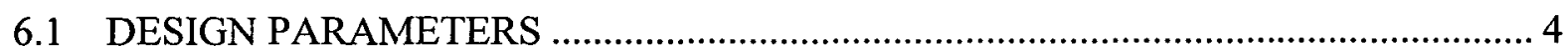

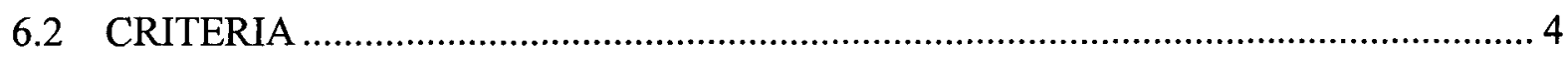

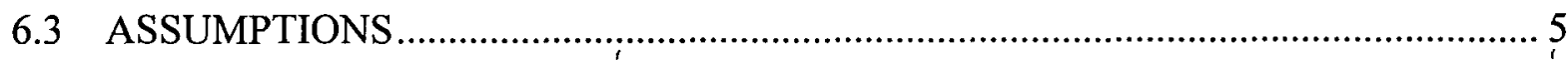

6.3.1 High-Value Property ............................................................................. 5

6.3.2 Limiting Fuel and Ignition Sources ...................................................... 6

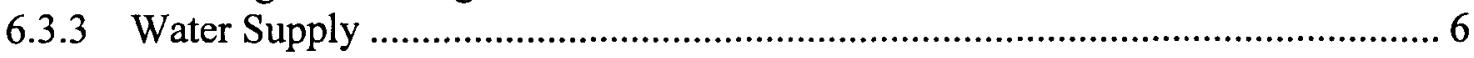

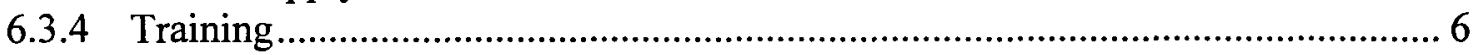

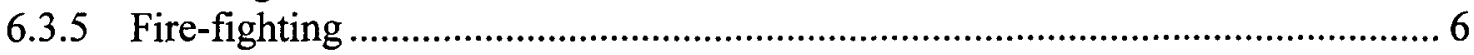

6.3.6 MPFL Estimate .................................................................................. 7

6.3.7 Impact on Site Characterization Study (Program Impacts) ........................... 8

6.4 CODES AND STANDARDS ........................................................................ 8

6.4.1 Code of Federal Regulations (CFR) ..................................................... 8

6.4.2 U.S. Department of Energy (DOE) ......................................................... 8

6.4.3 National Fire Protection Association (NFPA) ........................................ 8

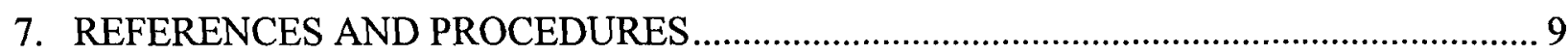

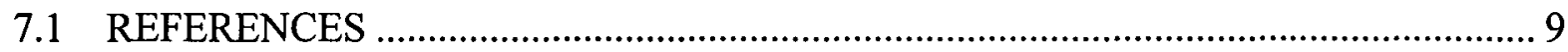

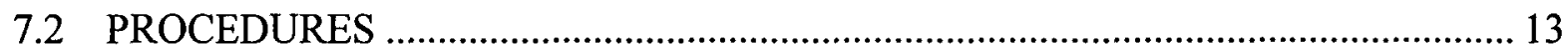

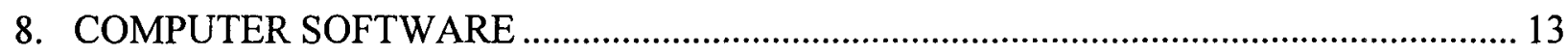

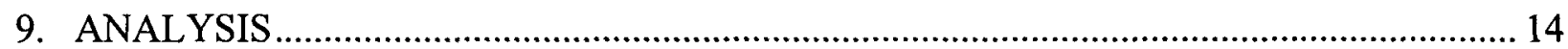

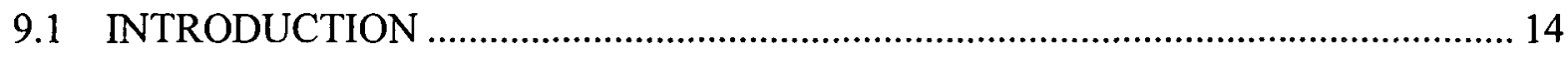

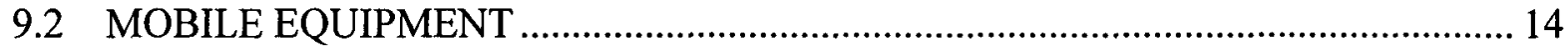

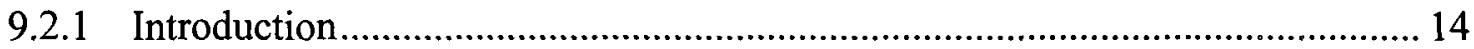

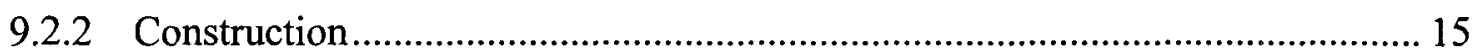

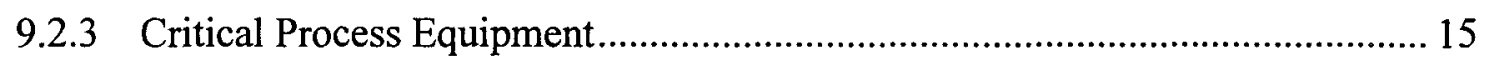

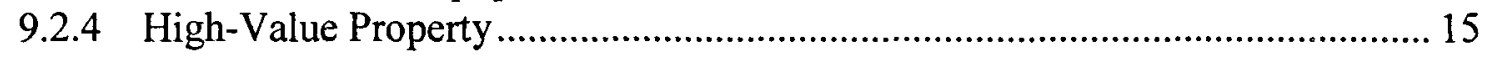

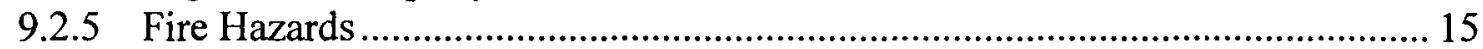

9.2.6 Operations ....................................................................................... 16

9.2.7 Potential for a Toxic, Biological and/or Radiation Incident Due to a Fire ........ 16 


\section{CONTENTS (Continued)}

9.2.8 Damage Potential Loss: Maximum Possible Fire Loss ..................................... 16

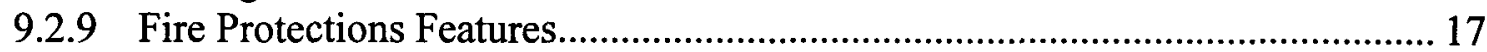

9.2.10 Protection of Essential Safety Class Systems ............................................... 18

9.2.11 Life Safety Considerations......................................................................... 18

9.2.12 Exposure Potential and the Potential for a Fire to Spread ................................. 18

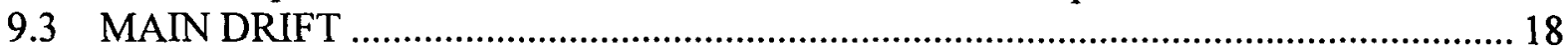

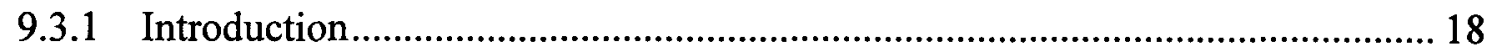

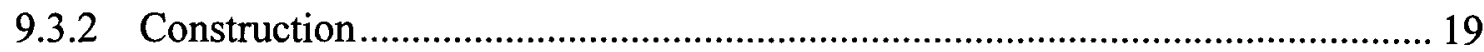

9.3.3 Critical Process Equipment....................................................................... 19

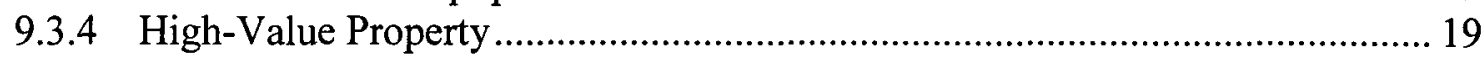

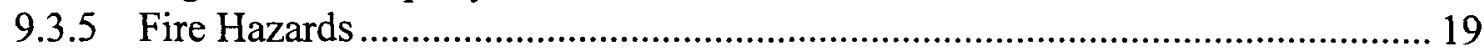

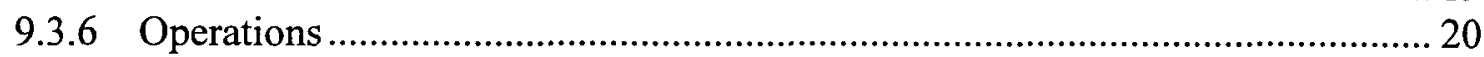

9.3.7 Potential for a Toxic, Biological and/or Radiation Incident Due to a Fire ........ 20

9.3.8 Damage Potential Loss: Maximum Possible Fire Loss ……………….......... 21

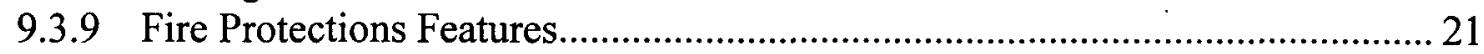

9.3.10 Protection of Essential Safety Class'Systems ………......................................... 22

9.3.11 Life Safety Considerations............................................................................ 22

9.3.12 Exposure Potential and the Potential for a Fire to Spread ................................. 24

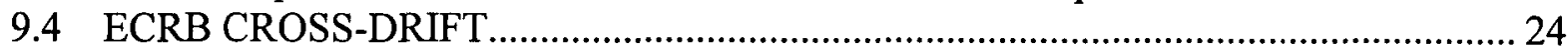

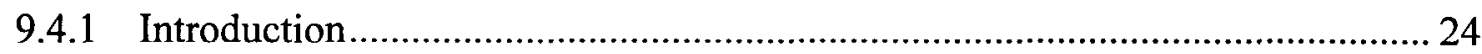

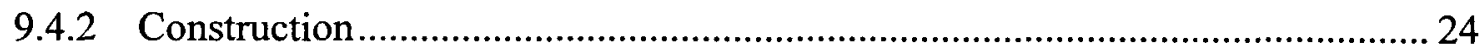

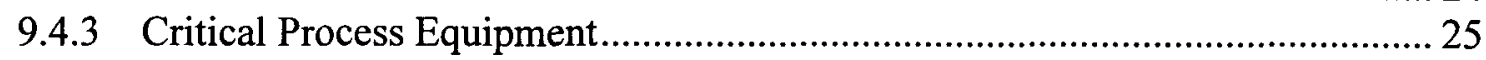

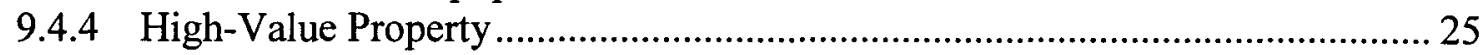

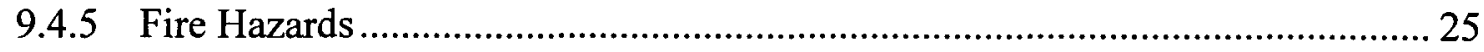

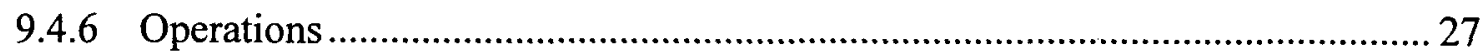

9.4.7 Potential for a Toxic, Biological and/or Radiation Incident Due to a Fire ........ 27

9.4.8 Damage Potential Loss: Maximum Possible Fire Loss ................................. 27

9.4.9 Fire Protections Features............................................................................... 28

9.4.10 Protection of Essential Safety Class Systems ……............................................ 29

9.4.11 Life Safety Considerations............................................................................. 29

9.4.12 Exposure Potential and the Potential for a Fire to Spread ................................. 31

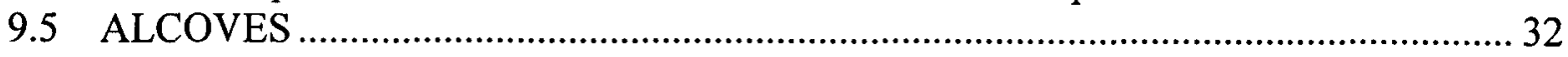

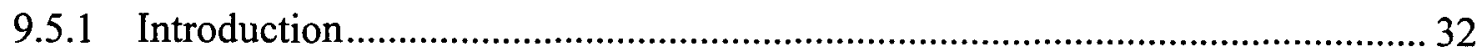

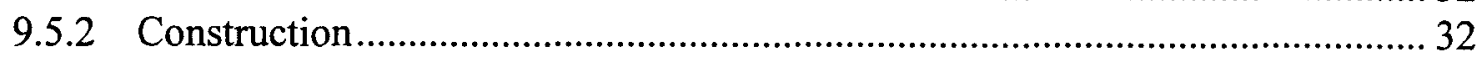

9.5.3 Critical Process Equipment...................................................................... 34

9.5.4 High-Value Property _......................................................................... 34

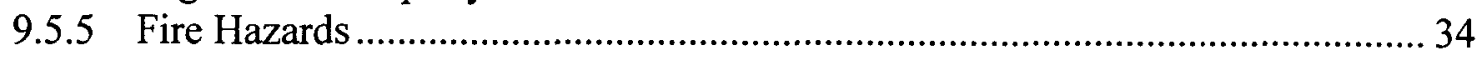

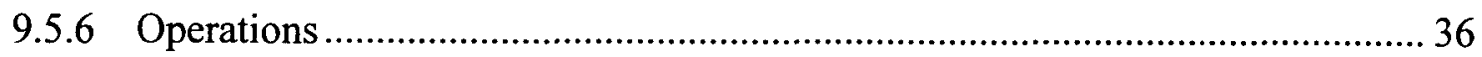

9.5.7 Potential for a Toxic, biological and/or Radiation Incident Due to a Fire......... 37

9.5.8 Damage Potential Loss: Maximum Possible Fire Loss ................................... 38

9.5.9 Fire Protections Features............................................................................ 38

9.5.10 Protection of Essential Safety Class Systems .................................................... 39

9.5.11 Life Safety Considerations............................................................................ 40 


\section{CONTENTS (Continued)}

9.5.12 Exposure Potential and the Potential for a Fire to Spread ................................ 41

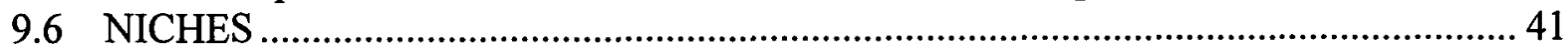

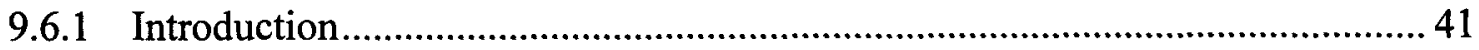

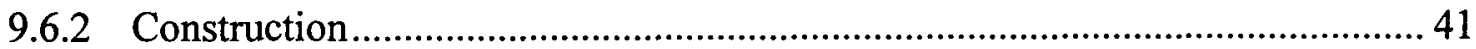

9.6.3 Critical Process Equipment............................................................................ 42

9.6.4 High-Value Property ..................................................................................... 42

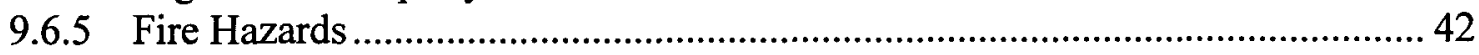

9.6.6 Operations …............................................................................................. 42

9.6.7 Potential for a Toxic, Biological and/or Radiation Incident Due to a Fire ........ 43

9.6.8 Damage Potential Loss: Maximum Possible Fire Loss .................................... 43

9.6.9 Fire Protections Features................................................................................... 44

9.6.10 Protection of Essential Safety Class Systems ………........................................ 45

9.6.11 Life Safety Considerations...............................................................................4 45

9.6.12 Exposure Potential and the Potential for a Fire to Spread ................................. 46

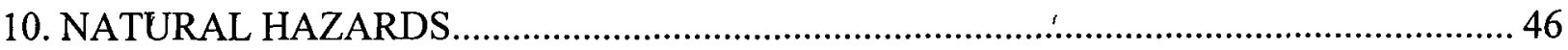

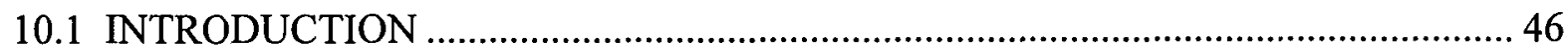

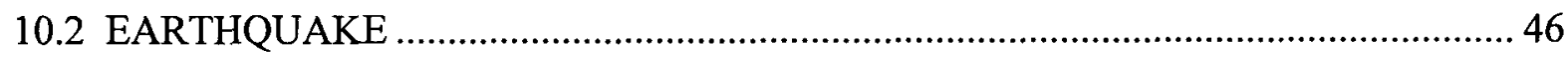

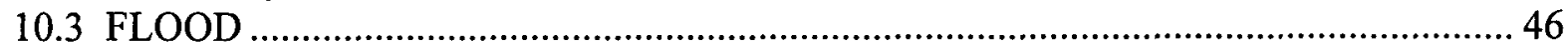

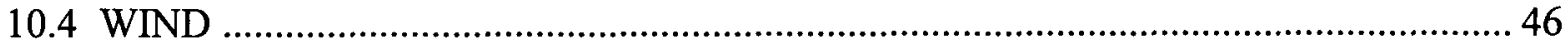

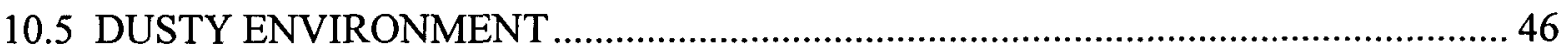

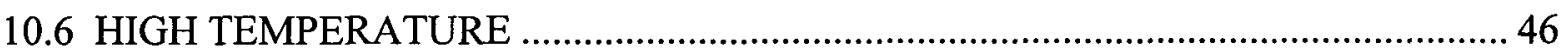

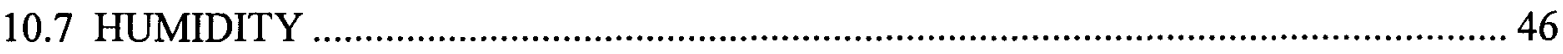

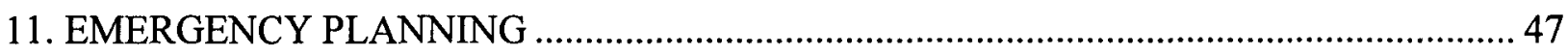

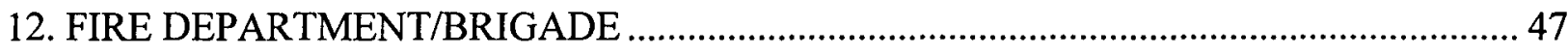

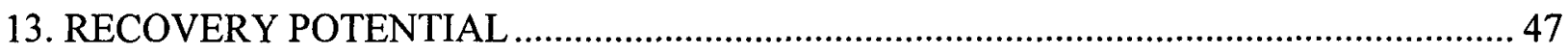

14. SECURITY AND SAFEGUARDS …………………....................................................... 47

15. EFFECT OF SIGNIFICANT FIRE SAFETY DEFICENCIES ON FIRE RISK ……............. 47

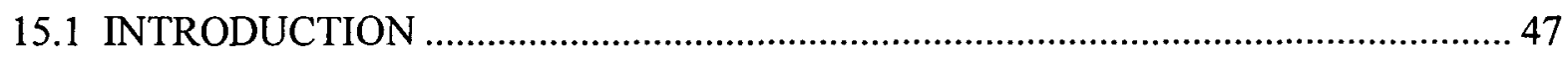

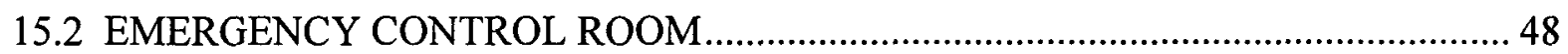

15.2.1 Current Status................................................................................................ 48

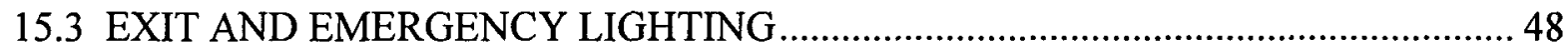

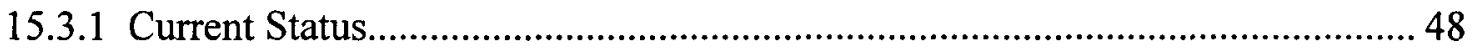

15.4 FIRE ALARM, EMERGENCY NOTIFICATION SYSTEM...................................... 49

15.4.1 Current Status............................................................................................. 49

15.5 PRE-ENGINEERED, ONBOARD, FIRE SUPPRESSION SYSTEMS ………............49

15.5.1 Current Status............................................................................................. 49

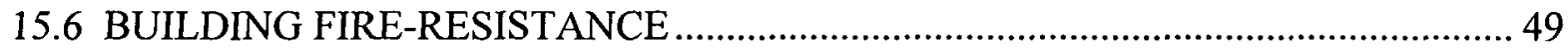

15.6.1 Current Status.................................................................................................... 49 


\section{CONTENTS (Continued)}

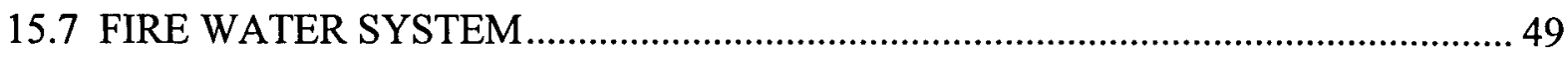

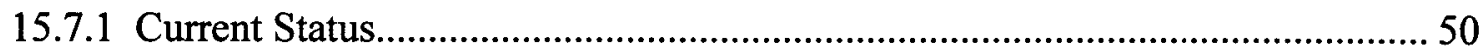

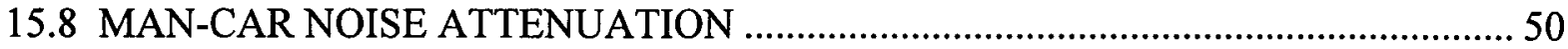

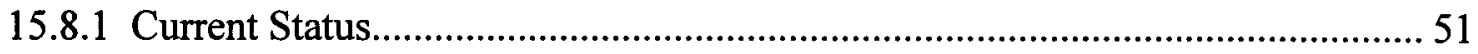

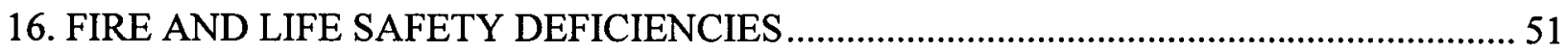

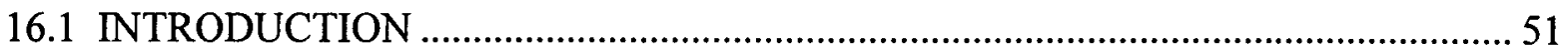

16.2 EMERGENCY REFUGE STATIONS IN THE ECRB CROSS-DRIFT ...................... 51

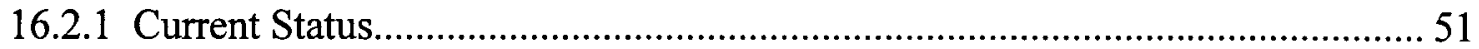

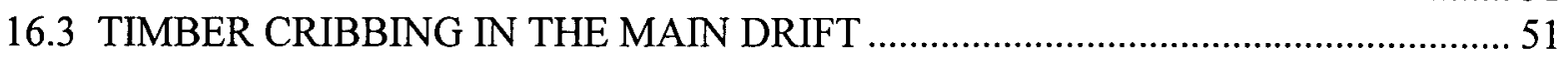

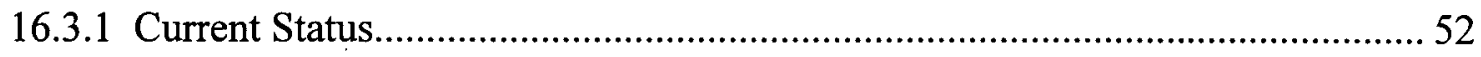

16.4 WATER AS A BACKUP FOR INCIPIENT FIRE FIGHTING ……........................ 52

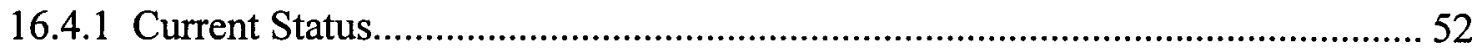

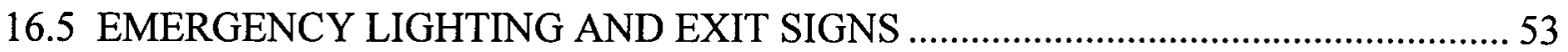

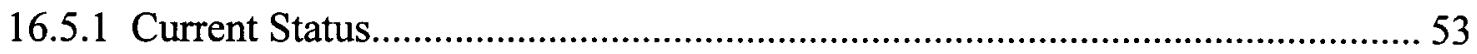

16.6 VISUAL WARNING SYSTEM AND STATUS INDICATORS …..............................53

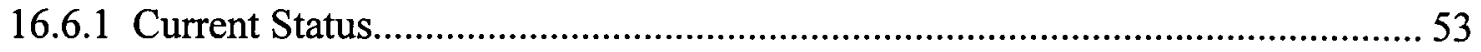

16.7 SMOKE DETECTOR SYSTEM IN ALCOVE 5 ………........................................ 53

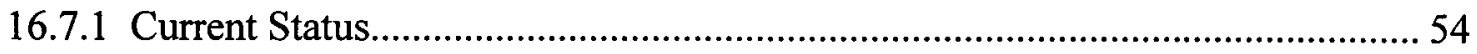

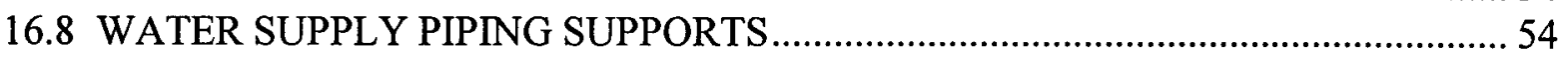

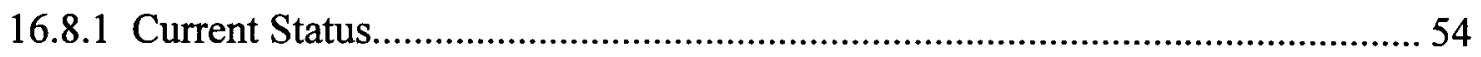

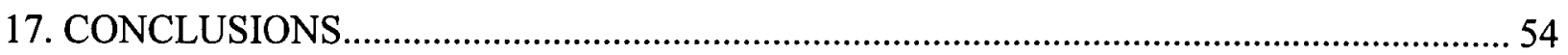

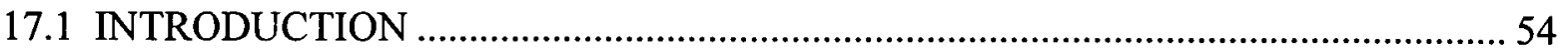

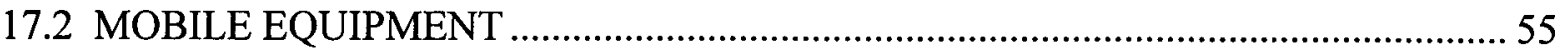

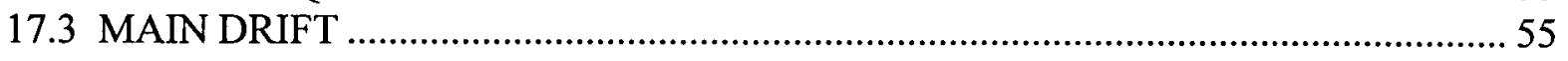

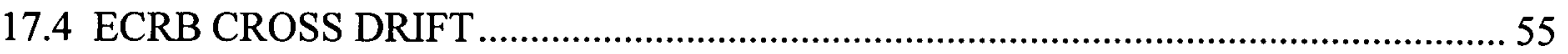

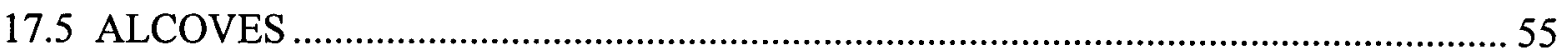

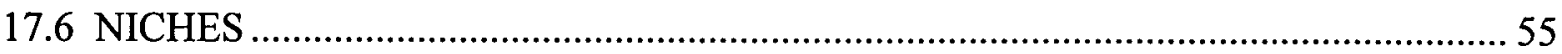

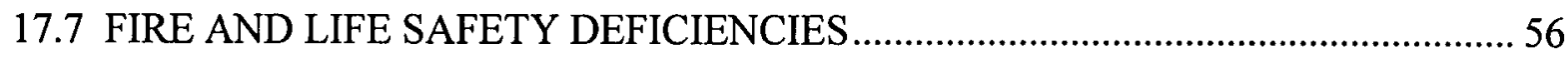

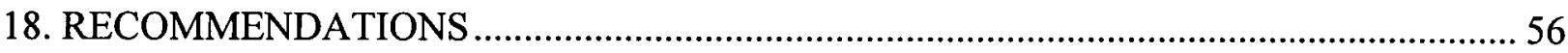

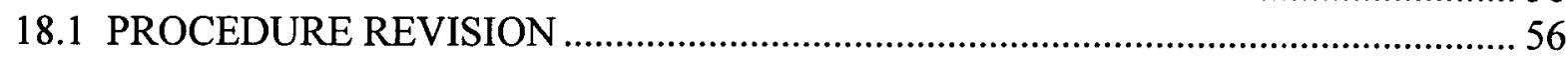

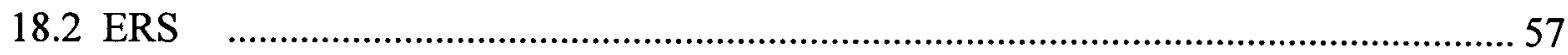

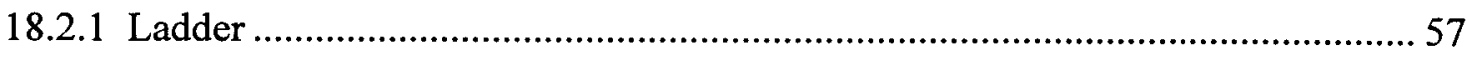

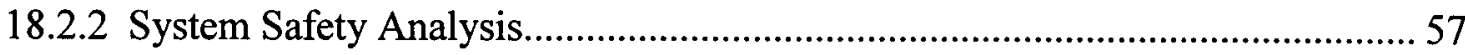

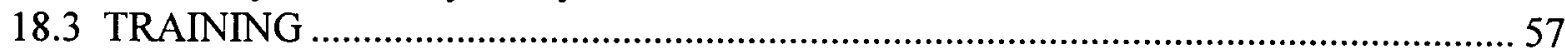

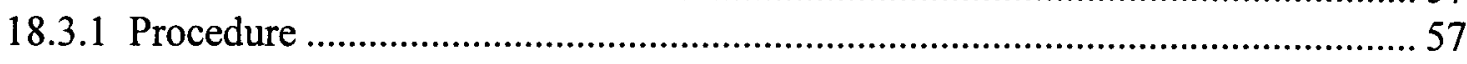

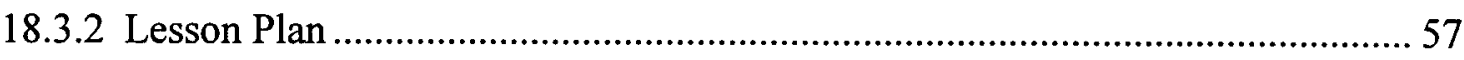

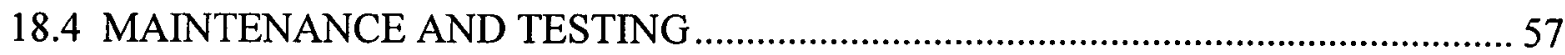

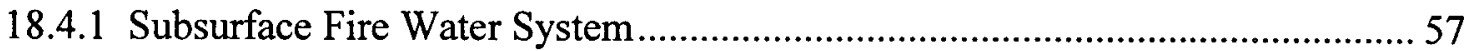

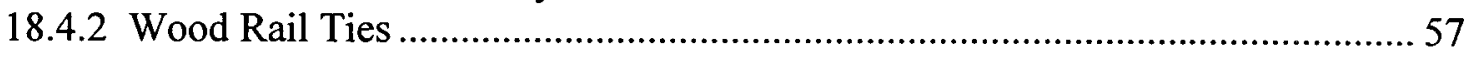




\section{TABLES}

Page

Table 9.2-1. Maximum Possible Fire Loss for Mobile Equipment .......................................... 17

Table 9.3-1. Maximum Possible Fire Loss for the Main Drift ................................................... 21

Table 9.4-1. Maximum Possible Fire Loss for the ECRB Cross-Drift .......................................... 28

Table 9.5-1. Maximum Possible Fire Loss for the Alcoves ........................................................ 38

Table 9.6-1. Maximum Possible Fire Loss for the Niches .......................................................... 44 


\section{ACRONYMS AND ABBREVIATIONS}

\section{ACRONYMS}

CFR

CRWMS

DBF

DOE

ECRB

ERS

ESF

ESFDR

FETD

FHA

FMRC

FY

LHD

$\mathrm{M} \& \mathrm{O}$

MPFL

MSHA

NEMA

NFPA

OSHA

PVC

SCSR

SFWS

SNPWS

TBM

TTF

UL

USGS

YMP YMSCO
Code of Federal Regulations

Civilian Radioactive Waste Management System

design basis fire

U.S. Department of Energy

Enhanced Characterization of the Repository Block

Emergency Refuge Station

Exploratory Studies Facility

Exploratory Studies Facility Design Requirements

Field Engineering Technical Document

Fire Hazard Analysis

Factory Mutual Research Corporation

fiscal year

load, haul, dump vehicle

Management and Operating Contractor

maximum possible fire loss

Mine Safety and Health Administration

National Electrical Manufacturers Association

National Fire Protection Association

Occupational Safety and Health Administration

polyvinylchloride

self-contained, oxygen-generating, self-rescuer

Subsurface Fire Water System

Subsurface Portion of the Non-Potable Water System

tunnel boring machine

thermal test facility

Underwriters Laboratories, Inc.

United States Geological Survey

Yucca Mountain Site Characterization Project

Yucca Mountain Site Characterization Office 
ABBREVIATIONS

1

liters

$1 / \mathrm{s}$

liters per second

$\mathbf{m}$

meters

$\mathrm{m}^{3}$

cubic meters

$\mathrm{yd}^{3}$

cubic yards 
INTENTIONALLY LEFT BLANK 


\section{OBJECTIVE}

The primary objective of this Fire Hazard Analysis (FHA) is to confirm the requirements for a comprehensive fire and related hazards protection program for the Exploratory Studies Facility (ESF) are sufficient to minimize the potential for:

- The occurrence of a fire or related event.

- A fire that causes an unacceptable on-site or off-site release of hazardous or radiological material that will threaten the health and safety of employees, the public or the environment.

- Vital U.S. Department of Energy (DOE) programs suffering unacceptable interruptions as a result of fire and related hazards.

- Property losses from a fire and related events exceeding limits established by DOE.

- Critical process controls and safety class systems being damaged as a result of a fire and related events.

(DOE Order 420.1, Section 4.2(1))

\section{SCOPE}

This FHA is revised to provide an up-to-date evaluation of hazards found in the current configuration and operation of the ESF. The FHA identifies deficiencies, and provides resolutions and mitigating measures for identified hazards. It specifically addresses the following items identified in the letter from Bechtel SAIC Company to the DOE (Williams 2001).

- The intended use of refuge chambers in the Cross-Drift.

- The use of timber cribbing ground support above the steel sets in isolated areas of the Main Drift.

- The use of water as a backup system for incipient fire fighting needs to be re-evaluated.

- The emergency lighting and exit lights have not been installed in the subsurface.

- The visual warning system and the facility control and status indicators, located in the North Portal Lamp Building not being complete.

- The smoke detector system, located in Alcove 5, while providing local alarm function, has not been connected to the control and status indicator panel.

- The water supply piping supports need to be reworked. 
This analysis includes the Enhanced Characterization of the Repository Block (ECRB) Cross-Drift, the Main Drift, Alcoves 1 through 10, and Niches 1 through 6.

This analysis includes Alcove 5 only to the extent it affects the Main Drift. The Thermal Test Facility (TTF), located in Alcove 5, is described in detail in a separate document titled Thermal Test Facility Fire Hazards Analysis, (CRWMS M\&O 1997c). The TTF FHA has been evaluated and has been determined to be current and adequate (Williams 2001).

\section{QUALITY ASSURANCE}

No quality assurance controls are applicable to the items or activities addressed in this fire hazards analysis. The items addressed in this technical report are temporary and are therefore not classified in accordance with QAP-2-3, Classification of Permanent Items, nor are any activities subject to the quality assurance requirements found in a Determination of Importance Evaluation. ESF subsurface fire protection has been examined in Determination of Importance Evaluation for the Subsurface Exploratory Studies Facility (CRWMS M\&O 1999a Section 6.17) and Determination of Importance Evaluation for the ESF Enhanced Characterization of the Repository Block Cross Drift, (CRWMS M\&O 2000a, Section 10.6.4) and the conclusions of ' these Determination of Importance Evaluations sufficiently bound this analysis. This report has been determined as not quality affecting (CRWMS M\&O 2000c, Addendum A - Work Package $6401226 \mathrm{CN} 2)$ and is therefore not subject to the requirements of the Quality Assurance Requirements and Description (QARD) document. (DOE 2000b).

This document was prepared in accordance with the Technical Work Plan for Test Facilities Design FY 01 Work Activities (CRWMS M\&O 2000c), Attachment 4 of Hazards Analysis System, AP-ESH-008 and Technical Reports, AP-3.11Q.

\section{METHOD}

This analysis is based on an analytical method that incorporates a review of applicable documents, regulations, orders, codes, and practices. In addition to document reviews, site visits were conducted on May 16, and August 20, 2001. Specific items observed during the site visits are documented throughout this FHA.

A search of off-project (non-CRWMS) literature (AP-3.11Q, Section 5.2f) was made but none are identified for review within this technical report. National Fire Protection Association codes and standards are considered off-project literature, but as these are the backbone of fire protection design bases, no special discussion is made.

The Lessons Learned Database was reviewed (AP-ESH-008, Section 5.1.1.4.b) for relevant information that could be incorporated or addressed in this FHA. The Lessons Learned Database contains numerous examples for employees to use in their daily work but none appeared to be relevant to this FHA. 
This analysis was prepared and checked by fire protection engineers, (qualified per AP-2.2Q), as directed by the DOE Order 420.1, Section 4.2.1(6), and as defined in DOE Standard DOE-STD-1066-99, Section 4.

\section{FIRE HAZARD ANALYSIS}

This FHA contains, but is not be limited to, a conservative assessment of the following fire safety issues:

- Description of construction

- Description of critical process equipment

- Description of high-value property

- Description of fire hazards

- Description of operations

- Potential for a toxic, biological and/or radiation incident due to a fire

- Damage potential: Maximum Possible Fire Loss (MPFL)

- Fire protection features

- Protection of essential safety class systems

- Life safety considerations

- Exposure fire potential and the potential for a fire spread between two fire areas

The fire safety items identified above are discussed in detail for the following: Mobile Equipment (Section 9.2), Main Drift (Section 9.3), ECRB Cross-Drift (Section 9.4), Alcoves (Section 9.5), and Niches (Section 9.6).

The fire safety items below are generic and apply equally to those areas described. They include:

- Natural hazards (earthquake, flood, wind) impact on fire safety (Section 10)

- Emergency planning (Section 11)

- Fire Department/Brigade response (Section 12)

- Recovery potential (Section 13)

- Security and Safeguards considerations related to fire protection (Section 14) 
- Effect of significant fire safety deficiencies on fire risk (Section 15)

(DOE G-420.1/B-0, Section IV, Paragraph 4.5).

Section 16, Conclusions, discusses whether the fire protection program objectives described in Section 1 have been met for each area of the ESF Subsurface.

\section{DESIGN INPUTS}

\subsection{DESIGN PARAMETERS}

The design of the Main Drift, ECRB Cross-Drift, Alcoves and Niches were developed in accordance with the design parameters identified in the applicable project procedures.

\subsection{CRITERIA}

The following design criteria, which are applicable to this analysis, were developed in response to requirements found in the Exploratory Studies Facility Design Requirements (ESFDR) (YMP 1997), and the Enhanced Characterization of the Repository Block Requirements Document (ECRB-RD) CRWMS M\&O 1998a)

- Alarm systems indicate monitored conditions. This item is inherent in the design of installed detection/alarm systems. (YMP 1997, 3.8.2.11.1.C)

- A life safety system shall be provided between the underground and surface. (YMP 1997, 3.8.2.11.1.D)

- Fire protection systems have been designed to detect, warn, control, and limit the impact of credible fires in the ESF. (YMP 1997, 3.8.2.9.1.B)

- Fire hose stations have been located to meet applicable safety requirements. (YMP 1997, 3.8.2.9.1.D)

- Subsurface fire protection system reliability is assured by mandatory use of Underwriters Laboratories (UL) listed and/or Factory Mutual Research Corporation (FMRC) approved components. This item is inherent in the design of installed detection/alarm systems and is used throughout this analysis. (YMP 1997, 3.8.2.9.1.E)

- Exit lighting, with battery backup, shall be provided to identify direction of evacuation to refuge chambers and/or shaft and ramp stations. Emergency lighting, with battery backup that is charged continuously by facility power, and actuates automatically, shall be provided in each shop, testing area, refuge chamber, and shaft and ramp station areas. (YMP 1997, 3.8.2.4.1.C \& .D) 
- The ESF fire protection systems will be installed to support scheduled testing programs as described in Appendix B to the ESFDR, and will not impair or preclude other associated testing and monitoring programs. (YMP 1997, 3.8.2.1.2.A)

- The ESF fire protection systems will be installed to allow dismantling and removal upon completion of designated operational functions. (YMP 1997/CRWMS M\&O 1998a, 3.8.2.1.2.D)

- The ESF fire protection systems will allow flexibility in the siting of final testing locations. (YMP 1997, 3.8.2.1.2.E)

- The ESF fire protection systems will be installed to support the testing utility requirements for testing programs described in Appendix B to the ESFDR. (YMP 1997/CRWMS M\&O 1998a, 3.8.2.1.2.G)

- The ESF fire protection systems will not require special facilities or equipment for service and maintenance. (YMP 1997, 3.8.1.2.C)

- The Uniform Building Code has no requirements for fire protection systems installed in tunnels. (YMP 1997, 3.2.1.2.4.A)

- The Occupational Safety and Health Program (AP-ESH-004) refers to DOE Order 420.1, Facility Safety, to establish facility safety requirements related to fire protection mitigation. (YMP 1997, 3.2.1.2.4C \& D)

- The impact on fire safety of natural hazards, such as, earthquakes, has been considered in the design of fire protection systems. (YMP 1997/CRWMS M\&O 1998a, 3.2.1.2.1.2.A)

- OSHA 29 CFR 1926 regulations are used as minimum governing criteria throughout this analysis and the construction in the tunnel. MSHA standards are incorporated in the tunnel design and operation as referenced by OSHA Standards. (YMP 1997, 3.2.1.1.2.4.H\&I; CRWMS M\&O 1998a, Derived 2)

- The presence of combustible materials underground during construction and operation is controlled and limited by administrative procedures. (YMP 1997, 3.2.1.2.3.C)

\subsection{ASSUMPTIONS}

\subsubsection{High-Value Property}

Assumption: High-Value property is assumed to be individual pieces of equipment and/or individual systems with a value exceeding $\$ 1$ million (DOE-STD-1066-99, Section 5.3.1). Used in Section 9.2.4, 9.3.4, 9.4.4, 9.5.4, and 9.6.4. 
Justification: The values used were included in the previous revision of this document and are duplicated in this revision. The assigned values do not require verification because they represent costs to establish a rough order-of-magnitude dollar estimate for property loss and only approximate values are required. An order of magnitude change in these values will not impact the conclusions of this FHA.

\subsubsection{Limiting Fuel and Ignition Sources}

Assumption: Fuel sources and ignition sources in the construction and test areas may be minimized by removal of all construction debris and by enforced administrative procedures, i.e., effective good housekeeping. Used throughout.

Justification: Section 3.2.1.2.3.C of the ESFDR limits and controls the presence of combustible materials underground during construction and operations. This is the most effective way of providing for hazard reduction.

\subsubsection{Water Supply}

Assumption: The 6-inch water distribution lines in the ESF Main Drift and the ECRB cross-drift, storage tank capacity, and pump size and head are sized to supply all anticipated fire protection water demand. Used throughout.

Justification: The existing system was evaluated in the Title III Evaluation Report for the Subsurface Fire Water System and Subsurface Portion of the Non-Potable Water System (CRWMS M\&O 1998f, Table 6-1) and was determined to be adequate. The ECRB Cross-Drift system is installed in accordance with the sizing criteria established in the Enhanced Characterization of the Repository Block, East-West Drift Utilities Design Analysis (CRWMS M\&O 1999b, Sections 7.2.1 and 7.2.2) and was designed to include the fire protection water demand.

\subsubsection{Training}

Assumption: Underground personnel have been trained in the use of portable fire extinguishers for fighting incipient stage fires. Used throughout.

Justification: BSC Training, in conjunction with Safety and Health, developed a training course for incipient stage fire fighting (CRWMS M\&O 1997b, Lesson Plan). The training course is mandatory for all on-site personnel. Instructional films on the use of portable fire extinguishers are included in the General Employee Training (GET) and in the General Underground Training (GUT) Training. The film is also included in both the annual GET and GUT Refresher training sessions. Used throughout.

\subsubsection{Fire-fighting}

Assumption: Site personnel will not directly engage subsurface fires beyond the incipient stage. Used throughout. 
Justification: “All Yucca Mountain Site Characterization Project organizations' fire fighting efforts are voluntary. These efforts are limited to a fire's incipient stage, and conducted by employees who have been trained in the general working principles of portable fire extinguishers and standpipe hose system use, as appropriate, including the hazards involved in incipient stage fire fighting. Employees may voluntarily engage fires only in the incipient stage when they are reasonably certain they can control the fire, and only after appropriate training. Employees not directly engaged in fighting an incipient stage fire are required to evacuate the affected area/facility. All employees shall evacuate the affected area/facility when a fire is beyond the incipient stage." (Dyer 2000)

\subsubsection{MPFL Estimate}

Assumptions: The MPFL is the value of property, excluding land value, within a fire area, unless a fire hazards analysis demonstrates a lesser (or greater) loss potential. This assumes the failure of both automatic fire suppression systems and manual fire fighting efforts (DOE-STD-1066-99, Section 4). The loss determination includes direct and indirect costs associated with the fire and clean-up operations (DOE G420.1/B-0, Section IV, 4.7). The equipment lost is assumed to have no salvage value. The assumed values for equipment include:

- $\$ 200,000$ for a locomotive

- $\$ 250,000$ for a $2.7 \mathrm{~m}^{3}\left(3.5 \mathrm{yd}^{3}\right)$ load, haul, dump (LHD)

- $\$ 75,000$ for the maintenance railcar

- $\$ 250$ per lineal foot of conveyor belting

- $\$ 10,000$ for scientific equipment located in Alcoves $1-4,6$ and 7

- $\$ 60,000$ for scientific equipment located in Alcove 8

- $\$ 25,000$ for scientific equipment located in Niche 3

- $\$ 20,000$ for scientific equipment located in Niche 4

- $\$ 40,000$ for scientific equipment located in Niche 5

Used in Tables 9.2-1, 9.3-1, 9.4-1, 9.5-1, and 9.6-1.

Justification: These assumed values provide a rough order-of-magnitude estimate. A reasonable estimate of cleanup is 75 percent of equipment value, and equipment replacement cost is 115 percent of equipment cost. The assumed values do not require verification because they represent assumed costs to establish a rough order-of-magnitude dollar estimate for property loss and only approximate values are required. An order of magnitude change in these values will not impact the conclusions of this FHA. 


\subsubsection{Impact on Site Characterization Study (Program Impacts)}

\subsubsection{Water}

Assumption: Water is acceptable as a backup fire suppression agent. Used throughout.

Justification: The Determination of Importance Evaluation for the Subsurface Exploratory Studies Facility states: "The use of fire suppression agents (including water) should be treated as a spill and dealt with accordingly" (CRWMS M\&O 1999a, Section 10.6.4). "Quantities of all materials used should be reported in accordance with the TFM Procedure." (CRWMS M\&O 2000a, Section 10.6.1)

\subsubsection{Dry Chemicals}

Assumption: Multipurpose dry chemical is acceptable as a fire suppression agent. Used throughout.

Justification: The Determination of Importance Evaluation for the Subsurface Exploratory Studies Facility states: “. . . potential impacts were bounded by an analysis showing that retention of fire suppression materials within the North Ramp will not impact potential radionuclide release and transport over a 10,000 year time period ..." "It was recommended, therefore, that water be used in conjunction with this fire-suppression material only if necessary for safety." (CRWMS M\&O 1999a, Section 11.3.3.3) (CRWMS M\&O 2000a, Section 11.3.3).

\subsection{CODES AND STANDARDS}

\subsubsection{Code of Federal Regulations (CFR)}

29 CFR $1910 \quad$ Occupational Safety and Health Standards, 1999

29 CFR 1926 Safety and Health Regulations for Construction, 1999

30 CFR Chapter 1 Mine Safety and Health Administration, 2000

\subsubsection{U.S. Department of Energy (DOE)}

DOE Order 420.1 Facility Safety, 1995, Change 3, 11-22-2000

DOE G-420.1/B-0 Implementation Guide, 1995

DOE-STD-1066-99 Fire Protection Design Criteria, 1999

\subsubsection{National Fire Protection Association (NFPA)}

NFPA 1 Fire Prevention Code, 2000

NFPA 14 Standard for the Installation of Standpipes and Hose Systems, 2000 
NFPA 17 Standard for Dry Chemical Extinguishing Systems, 1998

NFPA 30 Flammable and Combustible Liquids Code, 2000

NFPA $70 \quad$ National Electrical Code, 1998

NFPA 122 Standard for Fire Prevention and Control in Underground Metal and Nonmetal Mines, 2000

NFPA 385 Standard for Tank Vehicles for Flammable and Combustible Liquids, 2000

\section{REFERENCES AND PROCEDURES}

\subsection{REFERENCES}

29 CFR 1910. 1999. Labor: Occupational Safety and Health Standards. Readily available.

29 CFR 1926. 1999. Labor: Safety and Health Regulations for Construction. Readily available.

30 CFR Chapter 1.2000. Mineral Resources: Mine Safety and Health Administration. Readily available.

Broom, J.L. 2001. "Contract No. DE-AC08-01NV12101 - Submittal of Field Monthly Management Summary Status Report for the Month of March 2001." Letter from J.L. Broom (BSC) to S.P. Mellington (DOE/YMSCO), April 13, 2001, SSFS.04/01.006, with enclosure. ACC: MOL.20010529.0266.

CRWMS M\&O 1995a. Exploratory Studies Facility Package 2C, TS North Ramp Contact RBT Test Alcove GA Plan and Sections. BABEAF000-01717-2100-40149 REV 01. Las Vegas, Nevada: CRWMS M\&O. ACC: MOL.20000308.0221.

CRWMS M\&O 1995b. Exploratory Studies Facility Package 2C, TS North Ramp, Bow Ridge Fault Test Alcove GA Plan. BABEAF000-01717-2100-40147 REV. 02. Las Vegas, Nevada: CRWMS M\&O. ACC: MOL.19960520.0175.

CRWMS M\&O 1996a. ESF Layout Calculation. BABEAD000-01717-0200-00003 REV 04. Las Vegas, Nevada: CRWMS M\&O. ACC: MOL.19960930.0095.

CRWMS M\&O 1996b. Exploratory Studies Facility TS Main Drift Southern Ghost Dance Fault Alcove Enlarged Plan. BABEAF000-01717-2100-40247 REV 00. Las Vegas, Nevada: CRWMS M\&O. ACC: MOL.19970107.0057.

CRWMS M\&O 1997a. Exploratory Studies Facility TS Main Drift Northern Ghost Dance Fault Alcove Plan. BABEAF000-01717-2100-40232 REV 01. Las Vegas, Nevada: CRWMS M\&O. ACC: MOL.19970718.0132. 
CRWMS M\&O 1997b. Incipient Stage Fire Fighting Training. Lesson Plan SH97011. Las Vegas, Nevada: CRWMS M\&O. ACC: MOL.20010125.0038.

CRWMS M\&O 1997c. Thermal Test Facility Fire Hazards Analysis. BABFAH000-017170200-00002 REV 00. Las Vegas, Nevada: CRWMS M\&O. ACC: MOL.19980210.0742.

CRWMS M\&O 1997d. Exploratory Studies Facility, TS Main Drift, Drift Scale Flow Test Niches Plan and Sections. BABEAF000-01717-2100-40255 REV 00. Las Vegas, Nevada: CRWMS M\&O. ACC: MOL.19971007.0346.

CRWMS M\&O 1998a. Enhanced Characterization of the Repository Block Requirements Document (ECRB-RD). BAB000000-01717-5705-00013 REV 01. Las Vegas, Nevada: CRWMS M\&O. ACC: MOL.19980417.0713.

CRWMS M\&O 1998b. East-West ECRB Cross Drift Starter Tunnel Layout Analysis. BABEAF000-01717-0200-00008 REV 01. Las Vegas, Nevada: CRWMS M\&O. ACC: MOL.19980216.0530.

CRWMS M\&O 1998c. Response to Design Input Request CMO-12, 1/22/97. Input Transmittal CMO-15. Las Vegas, Nevada: CRWMS M\&O. ACC: MOL.19980311.0406.

CRWMS M\&O 1998d. Response to Design Input Request CMO-16, 2/23/98. Input Transmittal CMO-16. Las Vegas, Nevada: CRWMS M\&O. ACC: MOL.19980710.0127.

CRWMS M\&O 1998e. Response to Design Input Request CMO-9, 11/19/97. Input Transmittal CMO-14. Las Vegas, Nevada: CRWMS M\&O. ACC: MOL.19980311.0404.

CRWMS M\&O 1998f. Title III Evaluation Report for the Subsurface Fire Water System and Subsurface Portion of the Non-Potable Water System. BA0000000-01717-5705-00004 REV 0. Las Vegas, Nevada: CRWMS M\&O. ACC: MOL.19981007.0042.

CRWMS M\&O 1998g. Title III Evaluation Report for the Subsurface Lighting System. BABFAC000-01717-5705-00001 REV 00. Las Vegas, NV: CRWMS M\&O. ACC: MOL.19981120.0065.

CRWMS M\&O 1998h. Exploratory Studies Facility Cross Drift Alcoves/Niches Mechanical Utility Layout. BABFA0000-01717-2100-45318 REV 01. Las Vegas, Nevada: CRWMS M\&O. ACC: MOL.19990817.0248.

CRWMS M\&O 1999a. Determination of Importance Evaluation for the Subsurface Exploratory Studies Facility. BAB000000-01717-2200-00005 REV 07 ICN 03. Las Vegas, Nevada: CRWMS M\&O. ACC: MOL.19990728.0282.

CRWMS M\&O 1999b. Enhanced Characterization of the Repository Block, East-West Drift Utilities Design Analysis. BABFA0000-01717-0200-00002 REV 01. Las Vegas, Nevada: 
CRWMS M\&O. ACC: MOL.19990817.0219.

CRWMS M\&O 1999c. Exploratory Studies Facility Ventilation System Plan Including the Repository Block Cross Drift. BABFAD000-01717-4600-00001 REV 02. Las Vegas, Nevada: CRWMS M\&O. ACC: MOL.19990816.0220.

CRWMS M\&O 1999d. Transmittal of Shop Drawings, Equipment Data, Material Samples, or Manufacturer's Certificates of Compliance (SDT) for Exploratory Study Facility, Area 25. Transmittal No. 01-C027-1. Las Vegas, Nevada: CRWMS M\&O. ACC: MOL.19990727.0233.

CRWMS M\&O 2000a. Determination of Importance Evaluation for the ESF Enhanced Characterization of the Repository Block Cross Drift. BABEAF000-01717-2200-00011 REV 04 ICN 03. Las Vegas, Nevada: CRWMS M\&O. ACC: MOL.20000609.0264.

CRWMS M\&O 2000b. North Ramp 3.01X Areas Ground Support Analysis. BAB000000-017170200-00154 REV 00. Las Vegas, Nevada: CRWMS M\&O. ACC: MOL.20000627.0253.

CRWMS M\&O 2000c. Technical Work Plan For Test Facilities Design FY01 Work Activities. TWP-MGR-MD-000012 REV 00, Las Vegas, Nevada: CRWMS M\&O. ACC: MOL.20001108.0004.

CRWMS M\&O 2001. Vent 001, ECRB Refuge Chamber Calculation. Rev. 01. Las Vegas, Nevada: CRWMS M\&O. ACC: MOL.20010625.0299.

DOE (U.S. Department of Energy) 2000a. Emergency Management Plan. PLN-CRW-EM000001, Rev. 0. Las Vegas, Nevada: U.S. Department of Energy, Office of Civilian Radioactive Waste Management. ACC: MOL.20000801.0003.

DOE 2000b. Quality Assurance Requirements and Description. DOE/RW-0333P, Rev. 10. Washington, D.C.: U.S. Department of Energy, Office of Civilian Radioactive Waste Management. ACC: MOL.20000427.0422.

DOE G-420.1/B-0, G-440.1/E-0. 1995. Implementation Guide for Use with DOE Orders 420.1 and 440.1 Fire Safety Program. Washington, D.C.: U.S. Department of Energy. TIC: 242454.

DOE Order 420.1, Change 3. 2000. Facility Safety. Washington, D.C.: U.S. Department of Energy. Readily available.

DOE-STD-1066-99. 1999. Fire Protection Design Criteria. Washington, D.C.: U.S. Department of Energy. TIC: 249984.

Dyer, J.R. 2000. "Exploratory Studies Facility (ESF) Fire Fighting Policy." Letter from J.R. Dyer (DOE/YMSCO) to G. E. Dials (CRWMS M\&O), November 8, 2000, OPE:RBB-0104. ACC: MOL.20001204.0312. 
Factory Mutual Research. 2000. Belt Conveyors, Property Loss Prevention Data Sheets 7-11. [Johnson, Rhode Island]: FM Global. TIC: 250023.

Gwyn, D. W. 2001. "System Safety Evaluation of Relative Risk Associated with the Ground Support System in the 3.01X Areas." Interoffice correspondence from D.W. Gwyn (M\&O) to L.R. Morrison, January 24, 2001, LV.SA.RJG.01/01-001, with attachment. ACC:

MOL.20010226.0188.

McDonald, R.C. 1998a. "ECRB Cross Drift Railroad Ties." Letter from R.C. McDonald (CRWMS M\&O) to K.L. Limon (Kiewit/PB), February 10, 1998, LV.CM.RRD.2/98-031, with enclosure. ACC: MOL.19980219.0724; MOL.19980219.0725.

McDonald, R.C. 1998b. "Fire Suppression System for ECRB Conveyor." Letter from R.C. McDonald (CRWMS M\&O) to K.L. Limon, (Kiewit/PB), January 29, 1998, LV.CM.RRD.1/98041. ACC: MOL.19980213.0462.

McDonald, R.C. 1998c. "Requirements for Automatic Fire Suppression on U/G Heavy Diesel Equipment, Robbins TBM and Portable Diesel/Lube Car." Letter from R.C. McDonald (CRWMS M\&O) to K.L. Limon (Kiewit/PB), March 13, 1998, LV.CM.TJR.3/98-093. ACC: MOL.19980417.0289.

McDonald, R.C. 2001. "REVISED: Response to Opportunities for Improvement (OI)." Interoffice correspondence from R.C. McDonald (CRWMS M\&O) to A.S. Dodd, III, January 9, 2001, LV.SF.LCB.01/01-637. ACC: MOL.20010208.0064.

NFPA 1. 2000. Fire Prevention Code. 2000 Edition. Quincy, Massachusetts: National Fire Protection Association. TIC: 248642.

NFPA 122. 2000. Standard for Fire Prevention and Control in Underground Metal and Nonmetal Mines. 2000 Edition. Quincy, Massachusetts: National Fire Protection Association. TIC: 249675.

NFPA 14. 2000. Standard for the Installation of Standpipe, Private Hydrant, and Hose Systems. 2000 Edition. Quincy, Massachusetts: National Fire Protection Association. TIC: 249673.

NFPA 17. 1998. Standard for Dry Chemical Extinguishing Systems. 1998 Edition. Quincy, Massachusetts: National Fire Protection Association. TIC: 245935.

NFPA 30. 2000. Flammable and Combustible Liquids Code. 2000 Edition. Quincy, Massachusetts: National Fire Protection Association. TIC: 249674.

NFPA 385. 2000. Standard for Tank Vehicles for Flammable and Combustible Liquids. 2000 Edition. Quincy, Massachusetts: National Fire Protection Association. TIC: 249663. 
NFPA 70. 1998. National Electrical Code. 1999 Edition. Quincy, Massachusetts: National Fire Protection Association. TIC: 240528.

Williams, N.H. 2001. "Contract No. DE-AC08-01NV12101 - Fire Hazards Analysis Annual Review." Letter from N.H. Williams (BSC) to S.P. Mellington (DOE/YMSCO), March 27, 2001, PROJ.03/01.023. ACC: MOL.20010517.0264.

YMP (Yucca Mountain Site Characterization Project) 1997. Exploratory Studies Facility Design Requirements. YMP/CM-0019, Rev. 2, ICN 1. Las Vegas, Nevada: Yucca Mountain Site Characterization Office. ACC: MOL.19980219.0893; MOL.19960724.0138.

YMP 2000. Exploratory Studies Facility Package 1A, Starter Tunnel General Arrangement Plan (Sht. 2). YMP-025-1-MING-MG121, Rev. 04. Las Vegas, Nevada: Yucca Mountain Site Characterization Office. ACC: MOL.20000615.0037.

\subsection{PROCEDURES}

AP-2.2Q, Rev. 1. Establishment and Verification of Required Education and Experience of Personnel. Washington, D.C.: U.S. Department of Energy, Office of Civilian Radioactive Waste Management. ACC: MOL.20010724.0108.

AP-3.11Q, Rev. 2, ICN 0. Technical Reports. Washington, D.C.: U.S. Department of Energy, Office of Civilian Radioactive Waste Management. ACC: MOL.20010405.0010.

AP-SV.1Q, Rev. 0, ICN 2. Control of the Electronic Management of Information. Washington, D.C.: U.S. Department of Energy, Office of Civilian Radioactive Waste Management. ACC: MOL.20000831.0065.

AP-ESH-004, Rev. 0, ICN 1, BSCN 001, ECN 001. Occupational Safety and Health Program. Washington, D.C.: U.S. Department of Energy, Office of Civilian Radioactive Waste Management. ACC: MOL.20010709.0406.

AP-ESH-008, Rev. 0, ICN 1. Hazards Analysis System. Washington, D.C.: U.S. Department of Energy, Office of Civilian Radioactive Waste Management. ACC: MOL.20010828.0001.

LP-ESH-010-BSC, Rev. 1. Onsite Emergency Management, Washington, D.C.: U.S. Department of Energy, Office of Civilian Radioactive Waste Management. ACC: MOL.20010820.0147.

QAP-2-3, Rev. 10, ICN 0, BSCN 002. Classification of Permanent Items, Washington, D.C.: U.S. Department of Energy, Office of Civilian Radioactive Waste Management. ACC: MOL.20010212.0283.

\section{COMPUTER SOFTWARE}

Only commercial off-the-shelf software was used in the preparation of this technical report. No software routines or models were used and no calculations were performed. 
No controls are required for the management of electronic data transfer, per AP-SV.1Q, Control of the Electronic Management of Information (CRWMS M\&O 2000c, Section 10).

\section{ANALYSIS}

\section{$9.1 \quad$ INTRODUCTION}

This revised FHA technical report evaluates the fire hazards that may be encountered in the ESF and those fire protection features installed to mitigate those hazards. It includes the Topopah Spring Loop, referred to in this document as the Main Drift, (CRWMS M\&O 1996a, Figure 3), the ECRB Cross-Drift, (CRWMS M\&O 1998b, Figure 1), and Alcoves 1 through 10 and Niches 1 through 6, see Sections 9.5.2 and 9.6.2.

Although all of the areas discussed in this FHA comprise the subsurface facilities, for ease of locating information for specific areas it is divided into the following sub-sections:

$\begin{array}{ll}\text { Section 9.2 } & \text { Mobile Equipment } \\ \text { Section 9.3 } & \text { Main Drift } \\ \text { Section 9.4 } & \text {, ECRB Cross-Drift } \\ \text { Section 9.5 } & \text { Alcoves } \\ \text { Section 9.6 } & \text { Niches }\end{array}$

Each section is organized in the same order. If the reader wants information regarding what fire protection features are available for a specific area it is discussed in Sections 9.X.9, Fire Protection Features, in each sub-section. Sections 10 through 15 discuss topics common to all the sub-sections. These include natural hazards, emergency planning, fire department/brigade, recovery potential, security and safeguards, and significant deficiencies.

The fire protection systems are designed to provide life safety to underground personnel (employees and the public), property protection, and to support scheduled scientific testing programs.

Fire protection systems are designed to meet the criteria and assumptions defined in Section 6 of this analysis. To the extent practical, installation practices allow dismantling and salvage of the system components upon completion of their functional use in the ESF.

\subsection{MOBILE EQUIPMENT}

\subsubsection{Introduction}

This section describes equipment and components that are mobile and could be located anywhere in the Main Drift, the ECRB or adjacent to the entrance to any Alcove or Niche.

The mobile equipment includes the diesel locomotives and the maintenance railcar used to provide fuel and lubricants to the tunnel-boring machine and other equipment. This section describes each piece of equipment in sufficient detail to determine its impact as a fire hazard on 
the various areas of the sub-surface facilities. It also identifies the fire protection features, automatic, manual, and/or passive, to mitigate the identified hazards.

\subsubsection{Construction}

The construction of the mobile equipment is predominantly of steel and cast iron. There are minor quantities of exposed electrical wiring on each piece of equipment and some equipment utilizes rubber tires. All lubricants and fuels are contained within each piece of equipment.

\subsubsection{Critical Process Equipment}

None of the mobile equipment is considered critical process equipment.

\subsubsection{High-Value Property}

Mobile equipment does not meet the definition of high-value property (Assumption 6.3.1). For example, the estimated combined value of a locomotive and a maintenance railcar is approximately $\$ 275,000$. (Assumption 6.3.6)

\subsubsection{Fire Hazards}

The Fire Prevention Code (NFPA 1) defines a fire hazard as " . . . any situation, process, material, or condition that, on the basis of applicable data, may cause a fire or explosion or provide a ready fuel supply to augment the spread of intensity of the fire or explosion and that poses a threat to life or property." Based on this definition the following fire hazards have been identified in the Main Drift.

All of the elements necessary for a fire are found in the main drift. Construction and operation fuel sources include, the muck conveyor systems, combustible liquids, testing equipment, wiring insulation, rubber tires, and water and air hoses. Combustible liquids include diesel fuel, hydraulic fluid, grease and lubricating oil. Ignition sources may include faulting electrical equipment (motors, switches and transformers), welding and cutting operations, engine heat, and friction (brakes, bearings, gears and belting). Oxygen is supplied from ambient air.

Scenario 1 - A locomotive fire has the potential to propagate rapidly beyond the incipient stage. An onboard fire, probably in the engine compartment, should be contained and damage minimized, if operators act promptly to extinguish the fire with their portable extinguishers.

Scenario 2 - A fire resulting from an accident with the maintenance railcar, either during transportation in the drift or when transferring the combustible liquid contents of the onboard storage tanks to mobile equipment, has the potential to propagate rapidly beyond the incipient stage. The Field Engineering Technical Document (FETD) used this fire scenario to determine the duration of the design basis fire (DBF). The FETD provides the technical design basis for the proposed ERSs (CRWMS M\&O 2001).

The diesel locomotives carry approximately 189.31 (50 gal) of diesel fuel with lubricants in the wheel bearings and in other various components of the machine (site visit August 20, 2001). 
Heavy-duty diesel-powered mobile equipment, such as the $2.7 \mathrm{cu} . \mathrm{m}$ ( $3.5 \mathrm{cu} . \mathrm{yd}) \mathrm{LHD}$, carries 2351 (62 gal) of diesel fuel, 227 l (60 gal) hydraulic oil, has rubber tires, and wheel bearing greases (site visit August 20, 2001).

Quantities of combustible liquids such as, diesel fuel, lubricating oil and greases are limited, and any materials that might be stored underground are be kept in sealed containers, and separated from ignition sources (29 CFR 1926.800 (m) (NFPA 122). Containers are in accordance with NFPA 30 requirements. Sealed bearings are used, primarily for environmental containment, thus reducing exposure of greases.

A dedicated maintenance railcar consists of five storage tanks and one barrel. It will deliver hydraulic oil 285.5-1 (75.4 gal), lubricating oil 285.5-1 (75.4 gal), and a barrel of grease 82.5-1 $(21.8 \mathrm{gal})$ to refurbish the tunnel-boring machine and other miscellaneous pieces of equipment. This railcar also carries diesel fuel 467.8-1 (123.6 gal) for refueling mobile equipment. One tank is also provided for waste oil 285.51 (75.4 gal capacity) and one containing compressor oil, 285.5-1 (75.4 gal). The railcar has secondary spill containment. During the site visit of August 20,2001 it was determined the railcar was constructed by the on-site contractor with no documentation stating it was constructed to comply with NFPA 385 .

Refueling and maintenance of rolling stock and mobile equipment is conducted primarily on the surface, with small quantities of refueling underground possible.

\subsubsection{Operations}

The mobile equipment operating in the ESF transports site personnel to their work areas and, on occasion, visitors to Alcoves 2 and 5. In addition, mobile equipment transports material, fuel and maintenance materials to service equipment located anywhere within the sub-surface.

\subsubsection{Potential for a Toxic, Biological and/or Radiation Incident Due to a Fire}

The potential for a toxic, biological and/or radiation incident due to a fire involving mobile equipment is not considered a major hazard for the following reasons:

- Burning electrical cables can emit potentially toxic gases as products of combustion. The risk of combustion occurring is low, due to the use of cables consisting of fireresistant insulation of the self-extinguishing type and their small quantity.

- Biological materials are not present during construction and operation of the ESF.

- Radioactive materials are not present during construction and operation of the ESF.

- Rubber tires can emit potentially toxic gases as products of combustion. The risk of combustion occurring is low, due to the lack of an ignition source.

\subsubsection{Damage Potential Loss: Maximum Possible Fire Loss}

The MPFL for mobile equipment includes the replacement value of the LHD and a locomotive and the maintenance railcar and cleanup costs. This loss is described in Table 9.2-1. 
Table 9.2-1. Maximum Possible Fire Loss for Mobile Equipment

\begin{tabular}{|l|c|c|c|c|}
\hline $\begin{array}{c}\text { Equipment } \\
\text { Lost }\end{array}$ & $\begin{array}{c}\text { Equipment } \\
\text { Value }\end{array}$ & $\begin{array}{c}\text { Cleanup } \\
\text { Cost }\end{array}$ & $\begin{array}{c}\text { Replacement } \\
\text { Cost }\end{array}$ & MPFL \\
\hline Locomotive & $\$ 200,000$ & $\$ 150,000$ & $\$ 230,000$ & $\$ 380,000$ \\
\hline LHD (large) & $\$ 250,000$ & $\$ 187,500$ & $\$ 287,500$ & $\$ 475,000$ \\
\hline $\begin{array}{l}\text { Maintenance } \\
\text { Railcar }\end{array}$ & $\$ 75,000$ & $\$ 56,250$ & $\$ 86,250$ & $\$ 142,500$ \\
\hline $\begin{array}{l}\text { Combined } \\
\text { Loss }\end{array}$ & N/A & $\$ 393,750$ & $\$ 603,750$ & $\$ 997,500$ \\
\hline
\end{tabular}

\subsubsection{Fire Protections Features}

The fire protection features identified in this section are the installed mitigating features for the hazards identified in Section 9.2.5.

\subsubsection{Automatic}

The locomotive, maintenance railcar, and the LHD are protected by on-board, automatic fire detection systems and suppression systems (McDonald 1998c). It includes a pre-engineered, multipurpose dry chemical extinguishing system to protect the main hydraulic and lube oil systems. The system is designed to operate automatically or the operator can discharge the system manually (30 CFR 75.1911).

The maintenance railcar and the diesel-powered mobile equipment has been fitted with a pre-engineered multipurpose dry chemical extinguishing systems, installed in accordance with the Occupational Safety and Health Administration (OSHA)/MSHA regulations (29 CFR 1926.800(k)(10)(ii)/30 CFR 75.1911). The maintenance railcar is provided with an interlocked safety shut-off valve to shut-off the air supply to the fluid transfer pump(s). Even though the railcar storage tanks and transfer systems appear to be constructed by on-site personnel and there is no documentation that it complies with NFPA 385. The installation of the automatic suppression system, with interlock, makes the hazards manageable.

\subsubsection{Manual}

Each piece of mobile equipment carries a multipurpose, portable fire extinguisher. The minimum rating is 10A:60B:C. (30 CFR 75.1909(a)(2))

1-1/2 inch fire hose stations located at the entrance to each Alcove and at various locations throughout the Main Drift and ECRB Cross-Drift provide backup fire fighting capability. Hoses are also carried on the locomotives. Hoses are equipped with UL listed, electrically safe type nozzles. Each hose station installation has a pressure-reducing valve installed to ensure the nozzle pressure does not exceed 6.9 bar ga (100 psi) residual pressure (NFPA 14). Miners, locomotive operators and swampers who volunteer are trained in the use of fire hoses to fight incipient stage fires (McDonald 2001).

Incipient fire fighting response is not considered viable, unless personnel are immediately available at the time of ignition. 
Section 15.7 discusses whether the fire hose stations should remain in service or be removed.

\subsubsection{Passive}

The construction of the locomotives encloses the diesel engine with metal housings. The maintenance railcar is also constructed of noncombustible (steel and cast iron) materials.

\subsubsection{Protection of Essential Safety Class Systems}

The ESF is a non-nuclear facility. Radioactive materials are not present during construction and operation. Based on this, there is no essential safety class equipment, systems or components involved with the mobile equipment.

\subsubsection{Life Safety Considerations}

The mobile equipment does not have life safety considerations built into them to protect operating personnel and passengers from the effects of a fire. Personnel will follow exit signage directing them to the main drift, which will lead them to the surface.

\subsubsection{Exposure Potential and the Potential for a Fire to Spread}

Mobile equipment could be staged at any location in the Main Drift or in the ECRB Cross-Drift. It could also be adjacent to an Alcove or Niche when a fire occurs with the potential for a fire to spread to those areas. A fire in an Alcove or Niche has a low probability of spreading to the mobile equipment. The physical separation between the combustibles in these areas and the small quantity of in-situ and transient combustibles available minimizes the ability for a fire to spread.

\subsection{MAIN DRIFT}

\subsubsection{Introduction}

The ESF consists of an underground " $U$ " shaped configuration consisting of the North Ramp, the Main Tunnel and the South Ramp. The North Ramp and Main Tunnel contain a several alcoves and niches (CRWMS M\&O 1996a, Figure 3).

The length of the tunnel is approximately 7,877 $\mathrm{m}(25,837 \mathrm{ft})$ (CRWMS M\&O 1996a, Section 7.4.3) as measured from the north portal to the south portal. Tunnel excavation was performed using a $7.62 \mathrm{~m}$ ( $25 \mathrm{ft})$ diameter tunnel boring machine (TBM). Both the north and south ramps extend in a roughly westerly direction connecting to the Main Tunnel to define the eastern boundary of a potential repository. During construction of the Main Drift, excavated muck was removed from the ESF by a conveyor system for disposal at the surface. During the site visit it was observed that the conveyor system remains in the Main Drift, currently not being used, but is capable of restarting when the need is identified. Most of the construction materials, including ground support, are noncombustible. The exceptions are the muck conveyor belt and wiring insulation, which are of limited-combustible materials. 
The flow-through system provides ventilation of the ESF loop by use of two fans mounted on the portal side of the south ventilation bulkhead. The normal airflow direction is from the north portal to the south portal. The ventilation fans are reversible so the flow direction can be from the south portal to the north portal, if required under specific emergency conditions. Fan controls are located near the north portal and inside the south portal. Backup power is provided for the fans during utility power outages (CRWMS M\&O 1999c, Section 3.7).

\subsubsection{Construction}

The Main Drift was bored with a TBM. All walls, floors, and ceilings consist of solid rock. In various locations steel bracing with wood cribbing is used where the rock is unstable. Locations where wood cribbing is used are shown on CRWMS M\&O 2000b, Figure 1.

\subsubsection{Critical Process Equipment}

The Main Drift does not contain any critical process equipment.

\subsubsection{High-Value Property}

The high-value property includes the Main Drift subsurface muck conveyor. (Assumption 6.3.1)

\subsubsection{Fire Hazards}

The Fire Prevention Code (NFPA 1) defines a fire hazard as “ . . . any situation, process, material, or condition that, on the basis of applicable data, may cause a fire or explosion or provide a ready fuel supply to augment the spread of intensity of the fire or explosion and that poses a threat to life or property." Based on this definition the following fire hazards have been identified in the main drift.

Transient combustible materials such as paper, cardboard boxes, excess wood cribbing, plastics, etc., are limited and controlled by administrative procedure (AP-ESH-004, Section 5.13.1.1.d). Strict enforcement of "good housekeeping" rules appear effective in limiting the presence of transient combustibles.

All of the elements necessary for a fire are found in the main drift. Construction and operation fuel sources include, the muck conveyor systems, combustible liquids, plastics, PVC, rubber tires, testing equipment, excelsior (used behind cribbing in the $3.01 \mathrm{X}$ areas) wiring insulation, rubber tires, and water and air hoses. Combustible liquids include diesel fuel, hydraulic fluid, grease and lubricating oil. Ignition sources may include faulting electrical equipment (motors, switches, transformers and mine power centers), welding and cutting operations, engine heat, and friction (brakes, bearings, gears and belting). Oxygen is supplied from ambient air.

Scenario 1 - A locomotive fire has the potential to propagate rapidly beyond the incipient stage. An onboard fire, probably in the engine compartment, should be contained and damage minimized, if operators act promptly to extinguish the fire with their portable extinguishers. 
However, a diesel spill could release up to a tank full (189.3-1 [50 gal]) (See Section 9.2.5) of fuel into the bottom of the drift and any subsequent fire would likely spread quickly and exceed the operators' ability to contain it.

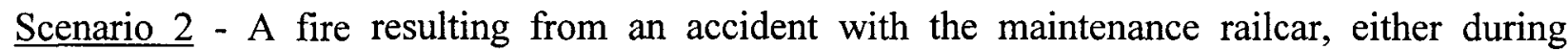
transportation in the drift or when transferring the combustible liquid contents of the onboard storage tanks to mobile equipment, has the potential to propagate rapidly beyond the incipient stage. Large quantities of fuel (See Section 9.2.5) could be released into the railcar's secondary containment or the bottom of the drift where any subsequent fire would spread quickly, involve adjacent equipment and exceed the operators' ability to contain it. The Field Engineering Technical Document (FETD) used this fire scenario to determine the duration of the design basis fire (DBF). The FETD provides the technical design basis for the proposed ERSs (CRWMS $\mathrm{M} \& \mathrm{O} 2001)$.

Scenario 3 - A mobile equipment fire has the potential to propagate beyond the incipient stage. An onboard fire should be contained and damage minimized if the operator and other personnel, in the area, act promptly to extinguish the fire. A fire, resulting from an accident involving other combustible materials, may propagate beyond the operator's ability to control.

Scenario 4 - A fire inside any power distribution equipment should be contained since the' equipment is housed in a heavy steel cabinet. Large transformers are dry type and are enclosed in NEMA 12 (dust tight) cabinets. Over-current and multiple relay protection, and current-limiting fuses are provided. Cabling consists of fire-resistant coatings that are of the self-extinguishing type.

Scenario 5 - A conveyor fire has the potential to propagate rapidly beyond the incipient stage. Conveyor fires are generally caused by faulting electrical equipment or friction at drives or pulleys.

\subsubsection{Operations}

The Main Drift provides access to and egress from the ECRB, the alcoves and the niches. The primary work is supporting post characterization testing.

All testing within the ESF is performed on the day shift. Occasionally, work may extend to or be scheduled on other shifts.

\subsubsection{Potential for a Toxic, Biological and/or Radiation Incident Due to a Fire}

The potential for a toxic, biological and/or radiation incident due to a fire is not considered a major threat for the following reasons:

- Burning electrical cables can emit potentially toxic gases as products of combustion. The risk of combustion occurring is low, due to the use of cables consisting of fireresistant insulation of the self-extinguishing type and by separating the power cables from the non fire-rated instrument cables.

- Biological materials are not present during construction and operation of the ESF. 
- Radioactive materials are not present during construction and operation of the ESF.

- Rubber tires can emit potentially toxic gases as products of combustion. The risk of combustion occurring is low, due to the lack of an ignition source.

\subsubsection{Damage Potential Loss: Maximum Possible Fire Loss}

The MPFL in the Main Drift includes a partial loss of the subsurface muck conveyor $365.7 \mathrm{~m}$ (1,200 feet), two levels of belting $182.9 \mathrm{~m}$ (600 feet) in length), cleanup, and equipment replacement costs. If a locomotive and the maintenance railcar are engaged in refueling the LHD they could be included in the MPFL. This loss is described in Table 9.3-1.

One of the largest area of the Main Drift with wood cribbing, installed to retain loose rocks (CRWMS M\&O 2000b, Figure 1) is approximately $182.9 \mathrm{~m}$ (600 feet) long. A small portion of the cribbing could be lost if the fire occurs in this area. This potential loss, due to its complexity, is not included in the MPFL.

Table 9.3-1. Maximum Possible Fire Loss for the Main Drift

\begin{tabular}{|l|c|c|c|c|}
\hline \multicolumn{1}{|c|}{$\begin{array}{c}\text { Equipment } \\
\text { Lost }\end{array}$} & $\begin{array}{c}\text { Equipment } \\
\text { Value }\end{array}$ & Cleanup & Replacement Cost & MPFL \\
\hline $\begin{array}{l}\text { Muck Conveyor } \\
\text { Belting 365.7 } \mathrm{m} \\
(1,200 \mathrm{ft})\end{array}$ & $\$ 300,000$ & $\$ 225,000$ & $\$ 345,000$ & $\$ 570,000$ \\
\hline LHD & $\$ 250,000$ & $\$ 187,500$ & $\$ 287,500$ & $\$ 475,000$ \\
\hline Locomotive & $\$ 200,000$ & $\$ 150,000$ & $\$ 230,000$ & $\$ 380,000$ \\
\hline Maintenance Railcar & $\$ 75,000$ & $\$ 56,250$ & $\$ 86,250$ & $\$ 142,500$ \\
\hline Combined Total Loss & N/A & $\$ 618,750$ & $\$ 948,750$ & $\$ 1,567,500$ \\
\hline
\end{tabular}

(Assumption 6.3.6)

\subsubsection{Fire Protections Features}

The fire protection features identified in this section are the installed mitigating features for the hazards identified in Section 9.3.5.

\subsubsection{Automatic}

Automatic fire detection, suppression and alarm systems are not installed in the Main Drift.

Diesel-powered mobile equipment has been retrofitted with onboard automatic fire suppression systems. (McDonald 1998c)

Automatic, pre-engineered multipurpose dry chemical suppression systems, which include manual actuating devices, are installed at all conveyor head, tail, drive and take-up pulleys (McDonald 1998b).

The conveyor system in the Main Drift is provided with slippage and alignment switches to stop the conveyor automatically before friction can start a fire. The conveyor is also interlocked to stop both upstream and downstream transport equipment in case of such a problem. 


\subsubsection{Manual}

Incipient fire fighting response is with portable fire extinguishers.

The portable multipurpose dry chemical fire extinguishers installed use "Ansul Foray" agent and have a UL rating of 10A:60B:C. Spacing between extinguishers exceeds $60 \mathrm{~m}(200 \mathrm{ft})$ in specific locations. Additional extinguishers are being installed this fiscal year bringing the ESF back into compliance.

To provide backup incipient fire fighting capability, 1-1/2 inch hose stations are installed in the Main Drift at the entrance to each alcove and at the entrance to the Cross-Drift. Locomotives also carry fire hoses that can be connected to the water line utility outlet. Each hose station includes a storage rack, a minimum of 150 feet of hose, with a UL listed, electrically safe shut-off type nozzle (NFPA 14). Each hose station installation has a pressure-reducing valve installed to ensure the nozzle pressure does not exceed 6.9 bar ga (100 psi) residual pressure (NFPA 14). Miners, locomotive operators, and swampers who volunteer are trained in the use of fire hoses to fight incipient stage fires (McDonald 2001).

Incipient fire fighting response is not considered viable, unless personnel are immediately available at the time of ignition, as there are no automatic fire detection systems or suppression systems installed in the main drift.

Section 15.7 discusses whether the fire hose stations should remain in service or be removed.

\subsubsection{Passive}

The walls, floor, and ceiling of the Main Drift are predominantly solid unsupported rock. In areas where the rock is unstable steel beams supporting wood cribbing is used to retain the rock. At specific alcoves and niches steel bulkheads are installed. These bulkheads, although not fire rated, will hinder the spread of fire either into the alcoves or niches or into the Main Drift from a fire in an alcove or niche.

\subsubsection{Protection of Essential Safety Class Systems}

The ESF is a non-nuclear facility and radioactive materials are not present during construction and operation. Therefore, no essential safety class equipment, systems or components are installed in the main drift.

\subsubsection{Life Safety Considerations}

\subsubsection{Ventilation}

The flow-through system will provide ventilation of the Main Drift by use of fans mounted on the portal side of the ventilation bulkhead. The bulkhead is at the South Portal so that normal airflow direction is from the North Portal to the South Portal. The ventilation fans are reversible so the flow direction can be from the south portal to the North Portal, if necessary for smoke removal. A backup generator is provided for the fan to maintain ventilation of the Main Drift loop during utility power outages (CRWMS M\&O 1999c, Section 3.7). 


\subsubsection{Egress}

The Main Drift is open at the north portal and is closed at the South Portal with dual, steel bulkheads. This provides two separate means of egress to escape a fire or other emergency. (LPESH-010-BSC, Attachment 2, section B.7)

\subsubsection{Personal Respiratory Protection}

All subsurface personnel are required to be trained in the use of, and to carry personal self-rescuers. The standard unit carried is suitable for escape from fire where there is sufficient oxygen. These units remove carbon monoxide generated in a fire and are rated for 60 minutes. These units do not include eye protection. Consequently, activity in even moderate amounts of smoke will be extremely difficult.

The walkout distance to the surface can be as great as $3,900 \mathrm{~m}$, half the length of the tunnel. Significant life safety improvements are achieved by providing all subsurface personnel the capability to use self-contained, oxygen-generating, self-rescuers (SCSRs). These units are National Institute for Occupational Safety and Health (NIOSH)/MSHA rated for 60 minutes of use in moderate to heavy working conditions but can be effective for up to 4 hours or longer when the wearer remains at rest or is breathing easily, as when awaiting rescue. They include eye goggles which makes escape in smoke possible. These SCSRs give personnel the means to walkout where travel times exceed 30 minutes, and protection against exposure to other harmful gases that may be present besides carbon monoxide. Currently a cache of SCSRs is located in Alcoves 5, 6, and 7 (LP-ESH-010-BSC, Attachment 2, Section B.9 second note)

\subsubsection{Emergency Refuge Stations (ERS)}

There are no Emergency Refuge Stations, also referred to as "Refuge Chambers" or "Refuge Areas," in the Main Drift. The project is committed to providing and maintaining a safe means of egress for all subsurface personnel. This commitment is met by providing SCSRs for all personnel. Combined with hazard mitigation by onboard, automatic, pre-engineered fire suppression systems, the ESF alarm/notification systems improvements (as yet uncompleted, see Section 9.3.11.5), this provides an acceptable level of personnel life safety.

\subsubsection{Alarm/Notification Systems}

Emergency communication is provided by an industrial paging/warning system. Emergency communication is provided by an industrial paging/warning system. To improve reliability, this system is connected to a separate dedicated cable system that is physically separated from the telephone cable system. It allows an individual to be paged, then respond and conduct a two-way conversation with the paging party. It has siren and flashing lights to provide audio and visual signaling (CRWMS M\&O 1999b, Section 7.5.4). This system provides telephone locations every $182.9 \mathrm{~m}$ (600 feet) (CRWMS M\&O 1998g, Section 7.1.2) throughout the Main Drift.

\subsubsection{Exit and Emergency Lighting}

All subsurface personnel are required to carry miners' lights or flashlights that provide emergency lighting. Exit lighting and emergency lighting, with battery backup, are currently 
being installed to supplement the miners' lights or flashlights (CRWMS M\&O 1999b, Sections 7.4.2.4 and 7.4.2.5) (CRWMS M\&O 1998g, Tables 6.1-1 and 6.2-1; Sections 7.1.1 and 7.1.2). Completion is scheduled for June 2, 2002 (Broom 2001).

\subsubsection{Exposure Potential and the Potential for a Fire to Spread}

The probability of a fire igniting in the main drift, due to exposure from an ongoing fire outside of either portal entrance, is extremely low. Surface facilities are of noncombustible construction and are physically separated from both tunnel entrances. OSHA regulations (29 CFR 1926.800 $(\mathrm{m})(7))$ also prohibit the storage of flammable and combustible materials close to the portals to reduce the possibility of a fire.

Fire propagation is limited in the drifts by adherence to strict regulations controlling the storage of flammable and combustible liquids. (29 CFR 1926.800(m)(7) (NFPA 30). The occurrence or spread of fire is minimized by requirements for containers and safe separation distances from ignition sources and explosives.

The most likely fire exposure potential to the Main Drift would be from an ECRB Cross-Drift fire. During the site visit it was noted there is a minimal quantity of combustibles located at the intersection of the two drifts. The fire exposure from the ECRB Cross-Drift is unlikely to be serious and would remain localized.

A fire in an alcove is unlikely to spread to the Main Drift due to the physical separation of the areas where combustibles are located in the alcove and their relationship to the Main Drift. Fire byproducts from such a fire would be spread rapidly throughout the Main Drift and downstream of the fire location by the main ventilation system.

\subsection{ECRB CROSS-DRIFT}

\subsubsection{Introduction}

The ECRB Cross-Drift consists of an "S" shaped drift (in plan view), connected to the Main Drift at approximately $1,990 \mathrm{~m}(6,527 \mathrm{ft})$ from the North Portal (CRWMS M\&O 1998b, Figure 1).

The length of the drift is approximately $2,800 \mathrm{~m}(9,184 \mathrm{ft})$ (CRWMS M\&O 1998b, Figure 1) as measured from the centerline of the Main Drift to the drift end. The ECRB Cross-Drift was excavated using a $5.0 \mathrm{~m}(16 \mathrm{ft} 5 \mathrm{in}$ ) diameter TBM (CRWMS M\&O 1998b, Section 7.2.4).

\subsubsection{Construction}

The ECRB Cross-Drift was bored with a TBM. The walls, floors and ceilings consist of solid rock. Excavated muck was removed from the ECRB Cross-Drift by a conveyor system that dumped muck onto the ESF muck conveyor for transport to the surface for disposal. The muck conveyor is mounted on the right rib of the drift. A steel, open-grid, safety grating was installed along the left rib of the drift to provide a safe walkway for the ECRB Cross-Drift personnel. During the site visit it was observed that the conveyor system remains but is currently not being 
used but is capable of restarting when the need is identified. Most of the construction materials, including ground support, are noncombustible.

The exceptions are:

- Timber (fir, pine, and/or oak) used for the rail supports (ties) throughout the length of the cross-drift. The 8 -inch by 6 -inch supports were installed on 30 -inch centers. No ballast is used. The ties are coated with a fire-retardant material. (McDonald 1998a)

- Certain materials, such as the muck conveyor belt and wiring insulation, are limited-combustible materials.

\subsubsection{Critical Process Equipment}

The ECRB Cross-Drift does not contain any critical process equipment.

\subsubsection{High-Value Property}

High-value property is defined as having a value in excess of $\$ 1$ million (Assumption 6.3.1). This includes the ECRB TBM and its trailing, gear having a value of $\$ 5.25$ million (CRWMS M\&O 1998c, Items $1 \& 2$ ).

\subsubsection{Fire Hazards}

\subsubsection{Combustible Liquid Fire}

The ECRB tunnel-boring machine, currently stored in the ECRB Cross-Drift, carries the following quantities of combustible fluids in onboard reservoirs (CRWMS M\&O 1998c):

Hydraulic Fluid:

$\begin{array}{lrr}\text { Main: } & 2,2701 & (600 \mathrm{gal}) \\ \text { Rock Drills: } & 5701 & (150 \mathrm{gal}) \\ \text { Clamshell: } & 761 & (20 \mathrm{gal}) \\ \text { Conveyor Tailpiece: } & 381 & (10 \mathrm{gal}) \\ & 3031 & (80 \mathrm{gal})\end{array}$

In addition to the reservoirs, there are several gallons of fluid in the lines, pumps, cylinder accumulators, etc. The main hydraulic systems and the lube oil system are located at the front of the TBM.

The Fire Prevention Code (NFPA 1), defines a fire hazard as “ . . . any situation, process, material, or condition that, on the basis of applicable data, may cause a fire or explosion or provide a ready fuel supply to augment the spread of intensity of the fire or explosion and that poses a threat to life or property." Based on this definition the following fire hazards have been identified in the ECRB cross-drift. 
All of the elements necessary for a fire are found in Cross-Drift. Construction and operation fuel sources include, the muck conveyor systems, combustible liquids, plastics, PVC, rubber hoses, testing equipment, wiring insulation, rubber tires, and water and air hoses. Combustible liquids include diesel fuel, hydraulic fluid, grease and lubricating oil. Ignition sources may include faulting electrical equipment (motors, switches, transformers and mine power centers), welding and cutting operations, engine heat, and friction (brakes, bearings, gears and belting). Oxygen is supplied from ambient air.

The TBM has the capacity to carry approximately 2,950-1 (780 gal) of AW46 hydraulic fluid (a high flash point, combustible liquid).

Scenario 1 - A locomotive fire has the potential to propagate rapidly beyond the incipient stage. An onboard fire, probably in the engine compartment, should be contained and damage minimized, if operators act promptly to extinguish the fire with their portable extinguishers. However, a diesel spill could release up to a tank full (189.3-1 [50 gal]), see Section 9.2.5, of fuel into the bottom of the drift and any subsequent fire would likely spread quickly and exceed the operators' ability to contain it.

Scenario 2 - A fire resulting from an accident with the maintenance railcar, either during transportation in the drift or when transferring the combustible liquids from the onboard storage tanks to mobile equipment, has the potential to propagate rapidly beyond the incipient stage. Large quantities of fuel, see Section 9.2.5, could be released into the railcar's secondary containment or to the bottom of the drift where the subsequent fire would spread quickly, involve adjacent equipment and exceed the operators' ability to contain it. The Field Engineering Technical Document (FETD) used this fire scenario to determine the duration of the design basis fire (DBF). The FETD provides the technical design basis for the proposed ERSs (CRWMS $\mathrm{M} \& O$ 2001).

$\underline{\text { Scenario } 3}$ - A mobile equipment fire has the potential to propagate beyond the incipient stage. An onboard fire should be contained and damage minimized if the operator and other personnel in the area act promptly to extinguish the fire. A fire, resulting from an accident involving other combustible materials, may propagate beyond the operator's ability to control it.

Scenario 4 - A fire inside any of the power distribution equipment should be contained since the equipment is housed in a heavy steel cabinet. Large transformers are dry type and are enclosed in dust free cabinets. Over-current and multiple relay protection, and current-limiting fuses are provided. Cabling consists of fire-resistant cable of the self-extinguishing type.

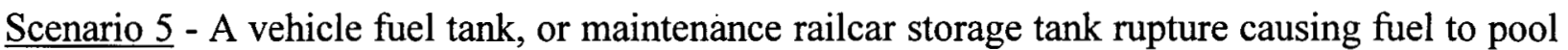
in and around the wood ties, which catches fire in the ECRB Cross-Drift has the potential to propagate rapidly beyond the incipient stage. Such a fire would likely rapidly consume the spilt fuel and cause some charring of ties in and immediately next to the fire. Since the ties are treated with a fire-retardant coating (a two-step process using a primer and final topcoat), it is unlikely that the fire would spread from tie to tie along the drift. However, energy re-radiation due to the confines of the small bore tunnel, and the high ventilation rate, could result in extension beyond the initial spill fire area. 


\subsubsection{Muck Conveyors}

Factory Mutual Research Corporation (FMRC) has conducted full-scale fire tests on designated fire-retardant belts on behalf of the United States Bureau Mines. All belts tested were ignitable and capable of propagating a fire when arranged in favorable burning configurations. Conveyor belts liberate dense, black, toxic smoke when ignited. FMRC cautions against ignoring belts because they are designated fire-retardant, when determining fire potential (FMRC 2000).

\subsubsection{Operations}

The primary work within the ECRB Cross-Drift consists of scientific investigation. In FY02 Alcove 10 will be constructed. Testing is performed mostly on the day shift but may extend to or be scheduled on the back shifts.

\subsubsection{Potential for a Toxic, Biological and/or Radiation Incident Due to a Fire}

The potential for a toxic, biological and/or radiation incident due to a fire is not considered a major threat:

- Most construction materials are essentially inert.

- Burning electrical cables can emit potentially toxic gases as products of combustion. The risk of combustion occurring is low, due to the use of cables consisting of fireresistant insulation of the self-extinguishing type and by separating the power cables from the non fire-rated instrument cables.

- Biological materials are not present during construction and operation of the ESF.

- Radioactive materials are not present during construction and operation of the ESF.

- Rubber tires can emit potentially toxic gases as products of combustion. The risk of combustion occurring is low, due to the lack of an ignition source.

\subsubsection{Damage Potential Loss: Maximum Possible Fire Loss}

If a fire ignites while the TBM is being serviced from the maintenance rail car, which is moved with a locomotive, all could be lost. In other scenarios individual pieces of equipment could be lost. In addition to the equipment lost a portion (200 feet, two levels 100 feet in length) of the conveyor belting, would be damaged by the fire. The value of these losses is described in Table 9.4-1. 
Table 9.4-1. Maximum Possible Fire Loss for the ECRB Cross-Drift

\begin{tabular}{|c|c|c|c|c|}
\hline $\begin{array}{c}\begin{array}{c}\text { Equipment } \\
\text { Lost }\end{array} \\
\end{array}$ & $\begin{array}{c}\text { Equipment } \\
\text { Value }\end{array}$ & Cleanup & $\begin{array}{c}\text { Equipment } \\
\text { Replacement }\end{array}$ & MPFL \\
\hline TBM $^{1}$ & $\$ 5,250,000$ & $\$ 3,937,500$ & $\$ 6,037,500$ & $\$ 9,975,000$ \\
\hline Maintenance Railcar & $\$ 75,000$ & $\$ 56,250$ & $\$ 86,250$ & $\$ 142,500$ \\
\hline Locomotive & $\$ 200,000$ & $\$ 150,000$ & $\$ 230,000$ & $\$ 380,000$ \\
\hline LHD & $\$ 250,000$ & $\$ 187,500$ & $\$ 287,500$ & $\$ 475,000$ \\
\hline $\begin{array}{l}\text { Conveyor Belting } \\
(200 \mathrm{ft})\end{array}$ & $\$ 50,000$ & $\$ 37,500$ & $\$ 57,500$ & $\$ 95,000$ \\
\hline Total Loss & N/A & $\$ 4,368,750$ & $\$ 6,698,750$ & $\$ 11,067,500$ \\
\hline
\end{tabular}

\subsubsection{Fire Protections Features}

The fire protection features identified in this section are the installed mitigating features for the hazards identified in Section 9.4.5.

\subsubsection{Automatic}

The automatic, pre-engineered dry chemical suppression systems on the TBM (CRWMS M\&O 1998d), muck conveyors (McDonald 1998b), and locomotives (CRWMS M\&O 1998e), and those installed on the diesel-powered mobile equipment and maintenance railcar (McDonald 1998c) use a multipurpose dry chemical as the fire suppression agent. These systems are installed in compliance with 29 CFR 1926.800 and NFPA 17 requirements.

Automatic, pre-engineered multipurpose dry chemical suppression systems, which include manual triggering devices, are installed at the conveyor head, tail, drive and take-up pulleys (McDonald 1998b).

\subsubsection{Manual}

Incipient fire fighting response is with portable multipurpose dry chemical fire extinguishers. The portable multipurpose dry chemical extinguishers installed in the ESF at $60 \mathrm{~m} \mathrm{(200 \textrm {ft } )}$ intervals along the length of the conveyors (29 CFR 1926.800). They use "Ansul Foray" agent and have a rating of 10A:60B:C. Spacing between extinguishers exceeds $60 \mathrm{~m}(200 \mathrm{ft})$ in specific locations. Additional extinguishers are being installed this fiscal year bringing the ESF back into compliance.

To provide backup incipient fire fighting capability, 1-1/2 inch hose stations are installed. Locomotives also carry fire hoses that can be connected to a water line utility outlet. Each hose station installation includes a storage rack, a minimum of $150 \mathrm{ft}$ of hose, with UL listed, electrically safe shut-off type nozzle. Each hose station has a pressure-reducing valve installed to ensure that the nozzle pressure does not exceed 6.9 bar ga (100 psi) residual pressure (NFPA 14). Miners, locomotive operators, and swampers who volunteer are trained in the use of fire hoses to fight incipient stage fires (McDonald 2001). 
Incipient fire fighting response is not considered viable, unless personnel are immediately available at the time of ignition, as there is no automatic fire detection systems or suppression systems installed in the main drift.

Section 15.7 discusses whether the fire hose stations should remain in service or removed.

\subsubsection{Passive}

The walls, floor and ceiling of the ECRB Cross-Drift are predominantly supported rock. Near the end of the ECRB Cross-Drift steel bulkheads are installed at Station 17+63 and Station 25+03 (CRWMS M\&O 1999d). These bulkheads, although not fire rated, will hinder the spread of fire.

The wooden railroad ties are coated with fire-retardant material (CRWMS M\&O 1998e).

\subsubsection{Protection of Essential Safety Class Systems}

The ESF is a non-nuclear facility and radioactive materials are not present during construction and operation. Therefore, no essential safety class equipment, systems or components are installed in the ECRB Cross-Drift.

\subsubsection{Life Safety Considerations}

\subsubsection{Ventilation}

The ECRB Cross-Drift ventilation system is a semi-independent system. The ECRB Cross-Drift ventilation system draws in fresh air from the north portal and supplies it to the operating face of the bulkhead at Station 17+63 (CRWMS M\&O 1999d). Exhaust air then returns to the north portal through its $1.2 \mathrm{~m}$ (48-inch) diameter ducting. Exhaust fans \#A, B, and C are operated to support the exhaust requirements of the cross-drift (CRWMS M\&O 1999c, Figure 1 and Section $3.5)$.

The Cross-Drift ventilation system is an extension of the exhaust system in the ESF tunnel, which includes reversibility of airflow as an operating feature. Under normal circumstances, Fans 1, 2, and 3 in the Main Drift and Fans A, B, C, and D in the Cross-Drift operate continuously to satisfy the ventilation requirements of the Cross-Drift by exhausting about 37 $\mathrm{m}^{3} / \mathrm{s}(77,000 \mathrm{cfm})$ from the Cross-Drift. A manual damper and pitot tubes installed near the entrance to the Cross-Drift facilitate air balancing. (CRWMS M\&O 1999c, Section 3.5)

In the event of an upset occurrence that warrants operating the ventilation system with airflow direction reversed, the $12.47 \mathrm{kV}$ power supply to Fans 1 through 3 and Fans A through D will be momentarily interrupted, causing all of the fans to go "off-line" and become non-operative. Fan 1 can then be restarted manually in the reverse direction, causing the $1.67 \mathrm{~m}\left(66^{\prime \prime}\right)$ Main Drift header and the $1.2 \mathrm{~m}$ (48") Cross-Drift header to reverse their function and become supply air headers. Because the control damper located at the junction of the Cross-Drift is partially closed, this will cause air flow through the $1.2 \mathrm{~m}$ (48") header and into the Cross-Drift. The volume to the start of the ECRB Cross-Drift is about 40 percent of the fan capacity. (CRWMS M\&O 1999c, Section 3.5) 
The test of the reverse fan operations demonstrated that the system delivers about $6.6 \mathrm{~m}^{3} / \mathrm{s}$ $(14,000 \mathrm{cfm})$ to the start of the Cross-Drift using only Fan 1 located at Sta. $00+10$ in the Main Drift. The dampers in the ECRB duct reduce the volume available at the start of the Cross-Drift. Based on the computer models of the system, the air volume to the end of the drift at Sta. $25+50$ would be approximately $2.9 \mathrm{~m}^{3} / \mathrm{s}$ (6,200 cfm). (CRWMS M\&O 1999c, Section 3.5)

\subsubsection{Egress}

If a fire occurs between Alcove 8 and Station 17+63m of the ECRB, personnel located upstream of the fire can evacuate out of the ECRB Cross-Drift toward the North Ramp safely, because the fire byproducts will be vented directly to the North Portal. Once in the North Ramp, the choice of direction for evacuation of personnel will be determined by the status of the ventilation system and construction activities. Personnel located downstream of the fire will assemble behind the steel bulkhead at Station $17+63$ and wait until rescued or until the fire is extinguished.

If a fire occurs between Alcove 8 and the North Ramp, the egress of personnel in the ECRB will be prevented. Personnel will assemble behind the steel bulkhead located at Station 17+63 or in Alcove 8. There is a cache of SCSRs in Alcove 8 and Niche 5. Evacuation procedures for the ECRB are defined in LP-ESH-010-BSC, Attachment 3, Onsite Emergency Management.

\subsubsection{Personal Respiratory Protection}

All subsurface personnel are required to be trained in the use of, and to carry personal self-rescuers. The standard unit carried is suitable for escape from fire where there is sufficient oxygen. These units remove carbon monoxide generated in a fire and are rated for about 60 minutes. These units do not include eye protection. Consequently, activity in even moderate amounts of smoke will be extremely difficult.

The walkout distance from the end of the ECRB Cross-Drift to the surface can be as great as $4,800 \mathrm{~m}$. Significant life safety improvements have been achieved by providing all subsurface personnel the capability to use self-contained, oxygen-generating, self-rescuers (SCSRs). These units are NIOSH/MSHA rated for 60 minutes of use in moderate to heavy working conditions but can be effective for up to 4 hours or longer when the wearer remains at rest or is breathing easily, as when awaiting rescue. They include eye goggles which makes escape in smoke possible. These SCSRs give personnel the means to walkout where travel times exceed 30 minutes, and protection against exposure to other harmful gases that may be present besides carbon monoxide (LP-ESH-010-BSC, Attachment 2, Section 9).

\subsubsection{Emergency Refuge Stations}

The project is committed to providing and maintaining a safe means of egress for all subsurface personnel. This commitment is met in the ECRB by the installation of ERSs and by providing SCSRs for all personnel. This, combined with hazard mitigation by onboard, automatic, pre-engineered fire suppression systems, the ESF alarm/notification systems improvements (as yet uncompleted, see Section 9.3.11.5), provides an acceptable level of personnel life safety.

In the ECRB Cross-Drift two potential ERSs have been designated. One in Alcove 8 with the second located between bulkheads at Stations $17+63$ and 25+03. Both will have caches of 
SCSRs (CRWMS M\&O 2001). The design of the ERSs were informally reviewed during the preparation of this FHA and found to be deficient.

\subsubsection{Alarm/Notification Systems}

Emergency communication is provided by an industrial paging/warning system. To improve reliability, this system is connected to a separate dedicated cable system that is physically separated from the telephone cable system. It allows an individual to be paged, then respond and conduct a two-way conversation with the paging party. It has siren and flashing lights to provide audio and visual signaling (CRWMS M\&O 1999b, Section 7.5.4). This system is installed so that it can be heard to warn and alert all personnel working in the alcoves or niches during an emergency (CRWMS M\&O 1999b, Section 7.5.4).

\subsubsection{Exit and Emergency Lighting}

The exit and emergency lighting systems being installed in the ECRB Cross-Drift are described in the ECRB East-West Drift Utilities Design Analysis (CRWMS M\&O 1999b, Sections 7.4.2.4 and 7.4.2.5). Lighted exit signs are being installed at all intersections in the cross-drift. These inform personnel and visitors the direction to go to the ramp entrances/exits of the ESF (CRWMS M\&O 1998g, Section 7.1.1).

Emergency lighting with battery backup is being installed at each telephone station. Since telephones are installed at $180 \mathrm{~m}(600 \mathrm{ft})$ intervals this also illuminates the fire extinguisher at each station (CRWMS M\&O 1998g, Sections 7.1.2). It was observed during the site visit that the installation of these systems was incomplete. The installation of these systems is scheduled to be complete by June 3, 2002 (Broom 2001).

\subsubsection{Exposure Potential and the Potential for a Fire to Spread}

The probability of a fire igniting in the cross-drift, due to exposure from an ongoing fire outside the entrance to the drift is low. Combustible material in the drift opening is limited to the muck conveyor, wood railroad ties, electric cable, telephone wire and rubber hose connecting utility water from the Main Drift to the ECRB Cross-Drift piping. The ties are coated with fire-retardant material and it is unlikely that fire would spread from tie to tie along the cross-drift. However, due to energy re-radiation in the small tunnel there is a small risk that some fire spread along the ties could occur, if the adjacent fire energy and duration were high. The muck conveyor and electric cable are fire-resistant and there is only a small amount of telephone wire and rubber hose. The muck conveyor drive is protected by an automatic fire protection system. Other materials in the drift opening, such as compressed air and water piping, are of noncombustible construction.

A fire in Alcove 8 is unlikely to spread into the ECRB Cross-Drift due to the physical separation (by distance) of the areas where combustibles may be located and their relationship to the cross drift. 


\subsection{ALCOVES}

\subsubsection{Introduction}

The various alcoves described in this section were constructed to house a multitude of scientific experiments and data gathering. They vary from a visitor's alcove to percolation tests. Each alcove has a different configuration. A roadheader or a combination of roadheader/drill and blast methods were used to excavate the natural materials for the alcoves.

Alcove 5 is not discussed. For information regarding Alcove 5 see the Thermal Test Facility Fire Hazards Analysis (CRWMS M\&O 1997c).

\subsubsection{Construction}

The Alcoves were excavated using a roadheader and are of various lengths. The walls, floors and ceilings consist of solid rock. Most of the construction, including ground support, is of noncombustible materials.

\subsubsection{Alcove 1}

Alcove 1 is on the right rib of the main ESF drift, approximately $43 \mathrm{~m}$ (141 ft) from the North Portal in the starter tunnel section. The total length of the Alcove is approximately $23 \mathrm{~m}(75 \mathrm{ft})$

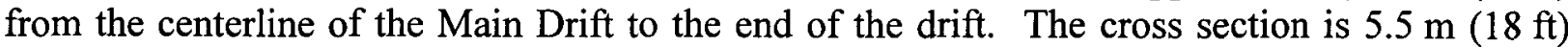
wide by $5.2 \mathrm{~m}(17 \mathrm{ft})$ high. A steel bulkhead is installed approximately $20 \mathrm{~m}(66 \mathrm{ft})$ from the Alcove entrance. (YMP 2000)

Ventilation air is blown into the Alcove from a duct connected to a dedicated fan/ducting system that supplies air to this alcove and to Alcove 2 (CRWMS M\&O 1999c, Figure 3).

\subsubsection{Alcove 2}

Alcove 2 is on the right rib of the main ESF drift. The Alcove consists of a straight drift connected to the Main Drift at approximately $168 \mathrm{~m}(551 \mathrm{ft})$ from the north portal. The total length of the Alcove is $48 \mathrm{~m}(157 \mathrm{ft})$ from the centerline of the Main Drift to the end of the drift.

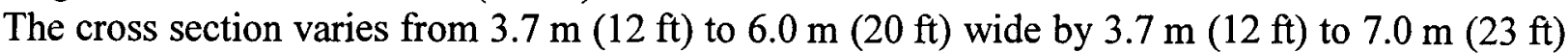
high. A security fence and gate are installed at the entrance to the Alcove. (CRWMS M\&O 1995b)

Ventilation air is supplied into the Alcove by a dedicated fan/ducting system. The fan is located upstream of Alcove 1 and also supplies Alcove 1. The fan intake extends to the portal entrance ensuring a fresh ventilation air supply to the Alcove, regardless of air quality in the Main Drift downstream of the north portal. The fan provides air supplied by ducting and to displace Alcove air back to the Main Drift (CRWMS M\&O 1999c, Figure 3).

\subsubsection{Alcove 3}

Alcove 3 is on the right rib of the main drift. The Alcove consists of a straight drift connected to

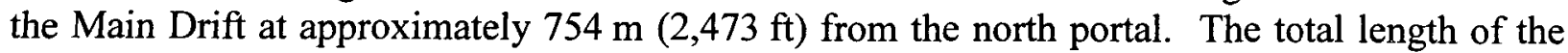


Alcove is $36.5 \mathrm{~m}$ ( $120 \mathrm{ft}$ ) from the centerline of the Main Drift to the end of the drift. The cross section is $5.0 \mathrm{~m}(16 \mathrm{ft})$ wide by $5.0 \mathrm{~m}(16 \mathrm{ft})$ high. (CRWMS M\&O 1995a)

A tee off the main ventilation duct to the North Portal ventilates the alcove. A damper at the entrance to the alcove regulates the volume of air pulled from the alcove (CRWMS M\&O 1999c, Figure 4, Section 3.9).

\subsubsection{Alcove 4}

Alcove 4 is on the right rib of the main drift. The Alcove consists of a straight drift connected to

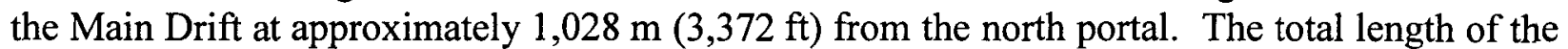
Alcove is $52 \mathrm{~m}(170 \mathrm{ft})$ from the centerline of the Main Drift to the end of the drift. The cross

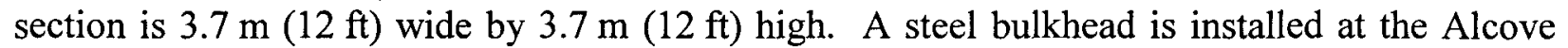
entrance. (CRWMS M\&O 1995a)

A tee off the main ventilation duct to the North Portal ventilates the alcove. A damper at the entrance to the alcove regulates the volume of air pulled from the alcove (CRWMS M\&O 1999c, Figure 5 and Section 3.10).

\subsubsection{Alcove 5}

The construction description for the TTF, Alcove 5 is included in the separate Thermal Test Facility Fire Hazards Analysis is essentially of the same type of construction as the other alcoves. (CRWMS M\&O 1997c)

\subsubsection{Alcove 6}

Alcove 6 is on the left rib of the main drift. The Alcove consists of an "L" shaped drift connected to the Main Drift at approximately $3,740 \mathrm{~m}(12,267 \mathrm{ft})$ from the north portal. The total length of the Alcove is $196 \mathrm{~m}$ (643 ft) from the centerline of the Main Drift to the end of the

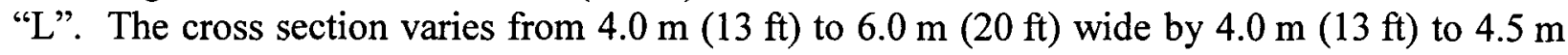
(15 ft) high (CRWMS M\&O 1997a).

The Alcove 6 ventilation fan and duct system provides air into the alcove, which is then exhausted back into the main ESF tunnel. A $90^{\circ}$ elbow and a short length of duct were added to the exhaust end of this duct to avoid the possibility of recirculation of air from this alcove. The fan is on a timer and operates only during the day shift. The operation is controlled by an automatic timer.(CRWMS M\&O 1999c, Figure 7, Section 3.12,).

\subsubsection{Alcove 7}

Alcove 7 is on the left rib of the main ESF drift. The Alcove consists of a straight drift connected to the Main Drift at approximately $5,060 \mathrm{~m}(16,600 \mathrm{ft})$ from the north portal. The total length of the Alcove is $125 \mathrm{~m}$ ( $410 \mathrm{ft}$ ) from the centerline of the Main Drift to the end of the drift. The cross section varies from $4.0 \mathrm{~m}(13 \mathrm{ft})$ to $6.0 \mathrm{~m} \mathrm{(20} \mathrm{ft)} \mathrm{wide} \mathrm{by} 4.0 \mathrm{~m}(13 \mathrm{ft})$ high. A $7.0 \mathrm{~m}(23 \mathrm{ft})$ deep turnaround bay is on the right rib of the Alcove at $25.5 \mathrm{~m}(84 \mathrm{ft})$ from the

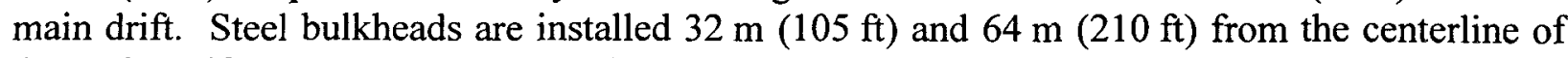
the Main Drift (CRWMS M\&O 1996b). 
Ventilation air is supplied from the Main Drift by a dedicated fan/ducting system. The fan/ducting system operates in exhaust mode, discharging directly into the Main Drift in the direction of the south portal (CRWMS M\&O 1999c, Figure 8, Section 3.13).

\subsubsection{Alcove 8}

Alcove 8 is constructed in the ECRB Cross-Drift. Percolation tests are being conducted in the alcove.

Ventilation air is supplied from the ECRB Cross-Drift with portable fans directing air into the alcove (site visit August 20, 2001).

\subsubsection{Alcove 9}

The Crest Alcove, Alcove 9, will conduct an unspecified scientific test when it's completed. It will be located in the ECRB Cross-Drift.

\subsubsection{Alcove 10}

Alcove 10 will house a mini-heater test when it's completed in FY02. It will be located in the ECRB Cross-Drift.

\subsubsection{Alcove 11}

Alcove 11 is in the planning stages and will house an unspecified test when completed.

\subsubsection{Critical Process Equipment}

There are numerous pieces of scientific data gathering equipment located in the various alcoves. Data is collected on a frequent, sometimes daily basis. While this equipment is required to gather data it is not considered critical process equipment.

\subsubsection{High-Value Property}

Property having a value in excess of $\$ 1$ million is considered high-value property (Assumption 6.3.1). No individual piece of equipment, system or component meets this definition.

\subsubsection{Fire Hazards}

\subsubsection{General}

The Fire Prevention Code (NFPA 1), defines a fire hazard as “. . .any situation, process, material, or condition that, on the basis of applicable data, may cause a fire or explosion or provide a ready fuel supply to augment the spread of intensity of the fire or explosion and that poses a threat to life or property." Based on this definition the following fire hazards have been identified in the alcoves.

All of the elements necessary for a fire are found in tunneling operations. ESF construction and operation fuel sources include, the muck conveyor systems, combustible liquids, plastics, PVC, 
rubber hoses, testing equipment, wiring insulation, rubber tires, and water and air hoses. Combustible liquids include diesel fuel, hydraulic fluid, grease and lubricating oil. Ignition sources may include faulting electrical equipment (motors, switches and transformers), welding and cutting operations, engine heat, and friction (brakes, bearings, gears and belting). Oxygen is supplied from ambient air.

\subsubsection{Alcoves 1 and 3}

There are only small amounts of limited-combustible material in either of these Alcoves. Testing activity in the Alcoves consists of periodic entry to monitor and record instrument readings.

\subsubsection{Alcove 2}

Exhibits/displays are mounted in steel tubular frames with composite materials for the display areas.

A section of the drift, approximately $8 \mathrm{~m}$ in length, has an area of steel sets with exposed timber ground support as part of the display.

\subsubsection{Alcove 4}

During the site visit it was observed that the primary source of fuel in Alcove 4 is a wood table used to support data gathering equipment.

\subsubsection{Alcove 5}

See the Thermal Test Facility Fire Hazards Analysis for details of hazards within the TTF. (CRWMS M\&O 1997c)

\subsubsection{Alcoves 6 and 7}

There are only small amounts of limited-combustible materials in either of these Alcoves. Testing activity in the Alcove consists of periodic entry to monitor and record instrument readings.

\subsubsection{Alcove 8}

Percolation tests are being conducted in the alcove. There is a small amount of limited-combustible materials in this Alcove.

\subsubsection{Alcoves 9 through 11}

Alcoves 9 through 11 have not completed construction as of the site visit. Therefore, no information is available to discuss the fire hazards located there. 


\subsubsection{Operations}

\subsubsection{Alcove 1}

Alcove 1 housed the United States Geological Survey (USGS) permeability test. All testing is complete and the alcove is idle.

\subsubsection{Alcove 2}

The USGS conducted test to determine hydrologic properties of the Bow Ridge Fault. All testing has been completed and the alcove is currently used as a visitor center. It has exhibits providing interactive presentations explaining why and how Yucca Mountain is being studied as a potential long-term repository for the storage of nuclear waste. No new construction or extensive testing is currently envisioned for this alcove.

\subsubsection{Alcove 3}

A radial borehole test is being conducted by the USGS in this alcove. Test monitoring activities continue. The alcove contains a small amount of scientific monitoring equipment, generally mounted in drill holes in the walls, with data recording equipment located on tables. The alcove is ventilated and while there are no personnel assigned to this area, small numbers of scientists enter to record data. Access to the alcove is unrestricted.

\subsubsection{Alcove 4}

Radial borehole test is being conducted by the USGS in this alcove. Test monitoring activities continue. This alcove contains a small amount of scientific monitoring equipment, generally mounted in drill holes in the walls, and data recording equipment. The alcove is ventilated. Access to the alcove is unrestricted.

\subsubsection{Alcove 5}

The operations conducted in Alcove 5 are described in the separate Thermal Test Facility Fire Hazards Analysis. (CRWMS M\&O 1997c)

\subsubsection{Alcove 6}

The USGS conducted tests to characterize the Ghost Dance Fault. The testing is complete and the alcove is idle.

\subsubsection{Alcove 7}

The USGS is now conducting tests to characterize the Ghost Dance Fault in this alcove. In-situ monitoring behind the alcove bulkhead continues. Two parallel bulkheads have been erected within the alcove, which restrict access to the rear portion of the alcove. Various scientific monitoring instruments have been mounted in the drift area between the bulkheads. Personnel access to this enclosed space is infrequent and required only if instruments fail or requires maintenance. The enclosed space is not ventilated and the only penetrations are for instrument 
cables. An attempt has been made to make the bulkheads airtight. Any entrance to the enclosed space requires re-establishment of ventilation prior to entry. The rest of the alcove houses a small amount of scientific monitoring and data collection equipment. The front portion of the alcove is ventilated and while there are no personnel assigned to this area, small numbers of scientists enter the alcove to record data for short periods of times. Access to the open portion of the alcove is unrestricted.

\subsubsection{Alcove 8}

The USGS/Berkeley are currently conducting water transport/permeability testing. Test monitoring activities continue.

\subsubsection{Alcove 9}

This alcove is to be constructed at a future date. When completed, scientists will conduct tests of an undetermined type.

\subsubsection{Alcove 10}

This alcove is to be completed at a future date. Upon its completion scientists will be conducting a mini-heater test.

\subsubsection{Alcove 11}

Alcove 11 is in the planning stages and will house an unspecified test when completed.

\subsubsection{Potential for a Toxic, biological and/or Radiation Incident Due to a Fire}

The potential for a toxic, biological and/or radiation incident due to a fire is not considered a major threat:

- Most materials of construction are essentially inert.

- Burning electrical cables can emit potentially toxic gases as products of combustion. The risk of combustion occurring is low, due to the use of cables consisting of fireresistant insulation of the self-extinguishing type and by separating the power cables from the non fire-rated instrument cables.

- Biological materials are not present during construction and operation of the ESF.

- Radioactive materials are not present during construction and operation of the ESF.

- Rubber tires can emit potentially toxic gases as products of combustion. The risk of combustion occurring is low, due to the lack of an ignition source. 


\subsubsection{Damage Potential Loss: Maximum Possible Fire Loss}

The value of scientific data lost due to a fire has not been determined for this analysis. All data is assumed collected and removed daily for storage outside the ESF. Therefore the potential loss of scientific data will be minimal. In the event of a fire, the impact to the program would be evaluated. Since the nature and extent of such an interruption is difficult to predict, this has neither been calculated nor considered for this analysis.

Rail mounted mobile equipment cannot enter an alcove, no rails have been installed. The roadheader could enter an alcove to perform excavation operations but in doing so all scientific equipment would have been removed prior to the excavation.

The MPFL for the alcoves is limited to scientific data collection equipment, miscellaneous support equipment, clean up and equipment replacement cost. The MPFL for each alcove is listed in Table 9.5-1. The values for equipment located in each alcove were obtained during the site visit and are rough order-of-magnitude estimates. A more refined estimate of this equipment will not impact the conclusions of this FHA. Alcoves are physically separated from each other a distance where a fire in one alcove will not impact another alcove. Therefore, the MPFL will only include the losses in a given alcove.

Table 9.5-1. Maximum Possible Fire Loss for the Alcoves

\begin{tabular}{|c|c|c|c|c|}
\hline Alcove No. & $\begin{array}{c}\text { Equipment } \\
\text { Value }\end{array}$ & Cleanup & $\begin{array}{c}\text { Equipment } \\
\text { Replacement }\end{array}$ & MPFL \\
\hline 1 & $\$ 10,000$ & $\$ 7,500$ & $\$ 11,500$ & $\$ 19,000$ \\
\hline 2 & $\$ 10,000$ & $\$ 7,500$ & $\$ 11,500$ & $\$ 19,000$ \\
\hline 3 & $\$ 10,000$ & $\$ 7,500$ & $\$ 11,500$ & $\$ 19,000$ \\
\hline 4 & $\$ 10,000$ & $\$ 7,500$ & $\$ 11,500$ & $\$ 19,000$ \\
\hline 5 & Note 1 & Note 1 & Note 1 & Note 1 \\
\hline 6 & $\$ 10,000$ & $\$ 7,500$ & $\$ 11,500$ & $\$ 19,000$ \\
\hline 7 & $\$ 10,000$ & $\$ 7,500$ & $\$ 11,500$ & $\$ 19,000$ \\
\hline 8 & $\$ 60,000$ & $\$ 45,000$ & $\$ 69,000$ & $\$ 114,000$ \\
\hline
\end{tabular}

(Assumption 6.3.6) Note 1 - See CRWMS M\&O 1997c.

\subsubsection{Fire Protections Features}

The fire protection features identified in this section are the installed mitigating features for the hazards identified in Section 9.5.5.

\subsubsection{Automatic}

No Alcoves have automatic fire detection or alarm capability other than Alcove 5. For a description of the automatic fire protection features of Alcove 5 refer to the Thermal Test Facility Fire Hazards Analysis (CRWMS M\&O 1997c). 


\subsubsection{Manual}

Incipient fire fighting response is with portable multipurpose dry chemical and clean-agent extinguishers. The portable multipurpose dry chemical extinguishers installed use "Ansul Foray" agent and have a UL rating of 10A:60B:C. Spacing between extinguishers does not exceed $60 \mathrm{~m}$ $(200 \mathrm{ft})$.

To provide backup incipient fire fighting capability, 1-1/2 inch hose stations are installed in the main drift, at the entrance to each Alcove. The same requirement is applicable in the cross-drift. Each installation includes a storage rack, a minimum of 150 feet of hose, with UL listed, electrically safe shut-off type nozzle. Each hose station has a pressure-reducing valve installed to ensure that the nozzle pressure does not exceed 6.9 bar ga (100 psi) residual pressure (NFPA 14). Miners, locomotive operators, and swampers who volunteer are trained in the use of fire hoses to fight incipient stage fires (McDonald 2001).

Section 15.7 discusses whether the fire hose stations should remain in service or be removed.

Incipient fire fighting response is not considered viable, unless personnel are immediately available at the time of ignition, as there is no automatic fire detection systems or suppression systems installed in any alcove other than Alcove 5.

\subsubsection{Passive}

In all alcoves the walls, floor and ceiling of the alcoves are predominantly supported rock. In Alcove 2 areas where the rock is unstable steel beams supporting wood cribbing is used to retain the rock. At specific alcoves steel bulkheads are installed. These bulkheads, although not fire rated, hinder the spread of fire either into the alcoves or into the drifts from a fire in an alcove.

In Alcove 2, the visitor's area, fire-resistant materials are used in the fabrication of the exhibits/displays. The frames are constructed of steel tubes. The cabinets are constructed of laminations of plywood and PVC covered by Acrovyn. Acrovyn is a trade name for an acrylic PVC alloy. It has a flame spread rating of 20. Fluorescent lights illuminate the displays. A small motor drives the rotating element. The interior of the cabinet is protected from fire by a coating of intumescent paint. Exhibit power requirement is 110 volts, at low wattage.

Lighting and power distributions are installed in accordance with National Electrical Code (NFPA 70) requirements. Emergency lights, with battery backup, are provided for Alcove 2.

\subsubsection{Protection of Essential Safety Class Systems}

The ESF is a non-nuclear facility and radioactive materials are not present during construction and operation. Therefore no essential safety class equipment, systems or components are located in any alcove. 


\subsubsection{Life Safety Considerations}

\subsubsection{Ventilation}

With two exceptions, the alcoves' ventilation systems are extensions of the ESF ventilation system. Each Alcove has its own ventilation system to ensure airflow to support test personnel and continuing construction activities. Air is taken from the Main Drift and exhausted back to it. The exceptions are Alcoves 1 and 2, which have a common fan/ducting system supplying fresh air from the north portal and exhausts it back to the main drift. (CRWMS M\&O 1999c, Section 3).

\subsubsection{Egress}

Each Alcove has a single means of egress available to escape a fire or other emergency (LPESH-010-BSC, Attachment 2, Section B, and Attachment 3). All egress is to and through the Main Drift or into the ECRB Cross-Drift to the main drift. Once in the main drift, two means of egress are available, one to the north portal, the other to the south portal.

\subsubsection{Personal Respiratory Protection}

All subsurface personnel are required to be trained in the use of, and to carry personal self-rescuers. The standard unit carried is suitable for escape from fire where there is sufficient oxygen. These units remove carbon monoxide generated in a fire and are rated for about 60 minutes. These units do not include eye protection. Consequently, activity in even moderate amounts of smoke will be extremely difficult.

The walkout distance to the surface can be as great as $3,900 \mathrm{~m}(12,795$ feet $)$, half the length of the tunnel. Significant life safety improvements are achieved by providing all subsurface personnel the capability to use self-contained, oxygen-generating, self-rescuers (SCSRs). These units are NIOSH/MSHA rated for 60 minutes of use in moderate to heavy working conditions but can be effective for up to 4 hours or longer when the wearer remains at rest or is breathing easily, as when awaiting rescue. They include eye goggles which makes escape in smoke possible. These SCSRs give personnel the means to walkout where travel times exceed 30 minutes, and protection against exposure to other harmful gases that may be present besides carbon monoxide.

A store of self-rescuers will be maintained in Alcove 2, in a sufficient quantity, to equip the maximum anticipated number of visitors.

\subsubsection{Emergency Refuge Stations}

The alcoves do not have ERS. Alcove 8 in the ECRB Cross-Drift has been designated an ERS.

\subsubsection{Alarm/Notification Systems}

Emergency communication is provided by an industrial paging/warning system. To improve reliability, this system is connected to a separate dedicated cable system that is physically separated from the telephone cable system. It allows an individual to be paged, then respond and 
conduct a two-way conversation with the paging party. It has siren and flashing lights to provide audio and visual signaling (CRWMS M\&O 1999b, Section 7.5.4). This system provides telephone locations every $182.9 \mathrm{~m}$ (600 feet) (CRWMS M\&O 1998g, Section 7.1.2) throughout the ECRB Cross-Drift and the Main Drift and in each Alcove.

\subsubsection{Exit and Emergency Lighting}

Emergency lighting, with battery backup, is provided in Alcove 2, Visitor Center.

Exit and emergency lighting, similar in scope to that proposed for the ECRB Cross-Drift have been installed in all other working Alcoves (CRWMS M\&O 1999b, Sections 7.4.2.4 and 7.4.2.5) (CRWMS M\&O 1998g, Section 7.1.1).

\subsubsection{Exposure Potential and the Potential for a Fire to Spread}

The probability of a fire igniting in any of the alcoves, due to exposure from an ongoing fire outside their entrance, is extremely low. Combustible material in the drift opening is limited to electric cable, telephone wire and rubber hoses connecting utility water from the Main Drift to the alcove piping. The electric cable is fire-resistant and there is only a small amount of telephone wire and rubber hose. Other materials in the drift opening, such as compressed air and water piping, are noncombustible. The more likely event is a fire inside an alcove that vents fire byproducts into the Main Drift and to downstream alcoves.

\subsection{NICHES}

\subsubsection{Introduction}

Niches are constructed by removing material from either the Main Drift or from the ECRB Cross-Drift. Drift scale flow tests are conducted in the niches (CRWMS M\&O 1997d).

\subsubsection{Construction}

The Niches were excavated with a roadheader. The walls, floors and ceilings consist of solid rock with rock-bolts used to stabilize the rock. Two niches, numbers 5 and 6 , will be installed in the ECRB Cross-Drift.

Niches 1,2,3, and 4 are of similar configurations and are located on the right rib of the main ESF drift. Approximate distances from the north portal are: Niche $1-3,570 \mathrm{~m}(11,710 \mathrm{ft})$; Niche 2 - 3,650 m (11,972ft); Niche 3 - 3,100 m (10,170 ft); and Niche 4 - 4,790 m (15,710 ft).

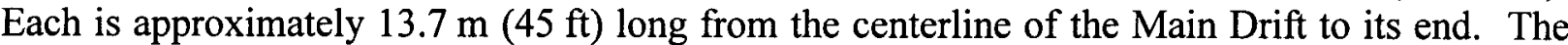
cross section is $4.0 \mathrm{~m}(13 \mathrm{ft})$ wide by $4.0 \mathrm{~m}(13 \mathrm{ft})$ high. Each Niche is sealed off from the Main Drift by a steel bulkhead. (CRWMS M\&O 1997d)

Niche 5 is in the ECRB Cross-Drift at STA $16+20 \mathrm{~m}$. Niche 6 is planned for the ECRB CrossDrift and will house an undetermined scientific test. 


\subsubsection{Critical Process Equipment}

There are numerous pieces of scientific data gathering equipment located in the various niches. Data is collected on a frequent, sometimes daily basis. While this equipment is required to gather data it is not considered critical process equipment.

\subsubsection{High-Value Property}

Property having a value in excess of $\$ 1$ million is considered high-value property (Assumption 6.3.1). No individual piece of equipment, system or component meets this definition.

\subsubsection{Fire Hazards}

The Fire Prevention Code (NFPA 1) defines a fire hazard as “. . . any situation, process, material, or condition that, on the basis of applicable data, may cause a fire or explosion or provide a ready fuel supply to augment the spread of intensity of the fire or explosion and that poses a threat to life or property." Based on this definition the following fire hazards have been identified in the niches.

All of the elements necessary for a fire are found in niches. Construction and operation fuel sources include, the muck conveyor systems, combustible liquids, plastics, PVC, rubber hoses, testing equipment, wiring insulation, rubber tires, and water and air hoses. Combustible liquids include diesel fuel, hydraulic fluid, grease and lubricating oil. Ignition sources may include faulting electrical equipment (motors, switches and transformers), welding and cutting operations, engine heat, and friction (brakes, bearings, gears and belting). Oxygen is supplied from ambient air.

There are only small amounts of limited-combustible materials in any of the niches. Testing activity in the niche consists of periodic entry to monitor and record instrument readings.

\subsubsection{Operations}

\subsubsection{Niches 1 and 2}

Niches 1 and 2 are essentially identical. A bulkhead has been erected across the entrance to both niches. All testing activities in these niches are complete and the niches are idle.

\subsubsection{Niche 3}

The testing in this niche, by the USGS/Berkeley, is in conjunction with the water transport/permeability testing in Alcove 8. Test monitoring activities continue.

\subsubsection{Niche 4}

Air testing is performed in this niche. Test monitoring activities continue. 


\subsubsection{Niche 5}

Air permeability testing and water transport tests of the lower lithophysal zone are performed in this niche. Test monitoring activities continue.

\subsubsection{Niche 6}

This planned niche has not been constructed. Upon completion it will house scientific testing.

\subsubsection{Potential for a Toxic, Biological and/or Radiation Incident Due to a Fire}

The potential for a toxic, biological and/or radiation incident due to a fire is not considered a major threat:

- Most materials of construction are essentially inert.

- Burning electrical cables can emit potentially toxic gases as products of combustion. The risk of combustion occurring is low, due to the use of cables consisting of fireresistant insulation of the self-extinguishing type and by separating the power cables from the non fire-rated instrument cables.

- Biological materials are not present during construction and operation of the ESF.

- Radioactive materials are not present during construction and operation of the ESF.

- Rubber tires can emit potentially toxic gases as products of combustion. The risk of combustion occurring is low, due to the lack of an ignition source.

\subsubsection{Damage Potential Loss: Maximum Possible Fire Loss}

The value of scientific data lost due to a fire has not been determined for this analysis. All data is assumed collected and removed daily for storage outside the ESF. Therefore the potential loss of scientific data will be minimal. In the event of a fire, the impact to the program would be evaluated. Since the nature and extent of such an interruption is difficult to predict, this has neither been calculated nor considered for this analysis.

The MPFL for the niches is limited to scientific data collection equipment, miscellaneous support equipment, clean up and equipment replacement cost. The MPFL for each niche is listed in Table 9.6-1. The values for the equipment located in each niche were obtained during the site visit and are rough order of magnitude estimates. A more refined estimate of this equipment will not impact the conclusions of this FHA. Niches are physically separated from each other a distance where a fire in one niche will not impact another niche. Therefore, the MPFL will only include the losses in a given niche. 
Table 9.6-1. Maximum Possible Fire Loss for the Niches

\begin{tabular}{|c|c|c|c|c|}
\hline Niche No. & $\begin{array}{c}\text { Equipment } \\
\text { Value }\end{array}$ & Cleanup & $\begin{array}{c}\text { Equipment } \\
\text { Replacement }\end{array}$ & MPFL \\
\hline 1 & N/A & N/A & N/A & N/A \\
\hline 2 & N/A & N/A & N/A & N/A \\
\hline 3 & $\$ 25,000$ & $\$ 18,750$ & $\$ 28,750$ & $\$ 47,500$ \\
\hline 4 & $\$ 20,000$ & $\$ 15,000$ & $\$ 23,000$ & $\$ 38,000$ \\
\hline 5 & $\$ 40,000$ & $\$ 30,000$ & $\$ 46,000$ & $\$ 76,000$ \\
\hline 6 & N/A & N/A & N/A & N/A \\
\hline
\end{tabular}

(Assumption 6.3.6)

\subsubsection{Fire Protections Features}

The fire protection features identified in this section are the installed mitigating features for the hazards identified in Section 9.6.5.

\subsubsection{Automatic}

There is no automatic, fire suppression or fire detection system installed in any niche.

\subsubsection{Manual}

Incipient fire fighting response is with portable multipurpose dry chemical extinguishers.

The portable multipurpose dry chemical extinguishers installed in the ESF use "Ansul Foray" agent and have a UL rating of 10A:60B:C. Spacing between extinguishers does not exceed $60 \mathrm{~m}$ $(200 \mathrm{ft})$.

To provide backup incipient fire fighting capability, 1-1/2 inch hose stations are installed in the main drift, near each niche. Each installation includes a storage rack, a minimum of $45.7 \mathrm{~m} \mathrm{(150}$ feet) of hose, with UL listed, electrically safe shut-off type nozzle. Each hose station is equipped with a pressure-reducing valve to ensure that the nozzle pressures does not exceed 6.9 bar $\mathrm{Ga}$. (100 psi) residual pressure (NFPA 14). Miners, locomotive operators, and swampers who volunteer are trained in the use of fire hoses to fight incipient stage fires (McDonald 2001).

Section 15.7 discusses whether the fire hose stations should remain in service or be removed.

Incipient fire fighting response is not considered viable, unless personnel were immediately available at the time of ignition, as there is no automatic fire detection systems or suppression systems installed in any niche.

\subsubsection{Passive}

The walls, floor and ceiling of the alcoves are predominantly solid unsupported rock. In areas where the rock is unstable steel beams are used to retain the rock.

Lighting and power distributions are installed in accordance with National Electrical Code (NFPA 70) requirements. 


\subsubsection{Protection of Essential Safety Class Systems}

The ESF is a non-nuclear facility and radioactive materials are not present during construction and operation. Therefore, no essential safety class equipment, systems or components is located in any niche.

\subsubsection{Life Safety Considerations}

\subsubsection{Ventilation}

No fixed ventilation system is required or provided for any niche. Temporary ventilation is provided, as needed, by a portable fan.

\subsubsection{Egress}

Each niche has a single means of egress available to escape a fire or other emergency (LP-ESH010-BSC, Attachment 2, Section B, and Attachment 3). All egress is to and through the Main Drift or into the ECRB Cross-Drift to the main drift. Once in the main drift, two means of egress are available, one to the north portal, the other to the south portal.

\subsubsection{Personal Respiratory Protection}

All subsurface personnel are required to be trained in the use of, and to carry personal self-rescuers.

The walkout distance to the surface can be as great as $3,900 \mathrm{~m}(12,795$ feet $)$, half the length of the tunnel. Significant life safety improvements are achieved by providing all subsurface personnel the capability to use self-contained, oxygen-generating, self-rescuers (SCSRs). These units are NIOSH/MSHA rated for 60 minutes of use in moderate to heavy working conditions but can be effective for up to 4 hours or longer when the wearer remains at rest or is breathing easily, as when awaiting rescue. They include eye goggles which makes escape in smoke possible. These SCSRs give personnel the means to walkout where travel times exceed 30 minutes, and protection against exposure to other harmful gases that may be present besides carbon monoxide.

\subsubsection{Emergency Refuge Stations}

The niches do not have ERS. All designated ERS are located in the ECRB Cross-Drift.

\subsubsection{Alarm/Notification Systems}

Emergency communication is provided by an industrial paging/warning system. To improve reliability, this system is connected to a separate dedicated cable system that is physically separated from the telephone cable system. It allows an individual to be paged, then respond and conduct a two-way conversation with the paging party. It has siren and flashing lights to provide audio and visual signaling (CRWMS M\&O 1999b, Section 7.5.4). This system provides telephone locations every $182.9 \mathrm{~m}$ (600 feet) (CRWMS M\&O 1998g, Section 7.1.2) throughout the ECRB Cross-Drift and the Main Drift and in each Niche. 


\subsubsection{Exit and Emergency Lighting}

The exit and emergency lighting for the Main Drift are utilized for the niches (CRWMS M\&O 1999b, Sections 7.4.2.4 and 7.4.2.5).

\subsubsection{Exposure Potential and the Potential for a Fire to Spread}

The probability of a fire igniting in any of the niches, due to exposure from an ongoing fire outside their entrance, is extremely low. There is only a small amount of limited-combustible material in the niches.

\section{NATURAL HAZARDS}

\subsection{INTRODUCTION}

The natural hazards described in the section are applicable to the Mobile Equipment, the Main Drift, ECRB Cross-Drift, the Alcoves and Niches described in Section 9.

\subsection{EARTHQUAKE}

Concerns regarding whether the installed water distribution system meets seismic design requirements were addressed in the Title III Evaluation Report for the Subsurface Fire Water System and Subsurface Portion of the Non-potable Water Supply (CRWMS M\&O 1998f). This report recommended the installation of seismic restraints to existing pipe support brackets to prevent detachment of the piping (CRWMS M\&O 1998f, Section 7.4).

\subsection{FLOOD}

Floods caused by natural causes are highly unlikely because of the limited precipitation and because the portals are above the probable maximum flood level (CRWMS M\&O 1998f, Table 6.1, Requirement 3.2.1.2.1.1.I).

\subsection{WIND}

Wind forces presents no problem to underground structures.

\subsection{DUSTY ENVIRONMENT}

A dusty environment has no impact on the fire protection systems located in the subsurface areas.

\subsection{HIGH TEMPERATURE}

High temperatures have no impact on the fire protection systems located in the subsurface areas.

\subsection{HUMIDITY}

Humidity has no impact on the fire protection systems located in the subsurface areas. 


\section{EMERGENCY PLANNING}

The operating contractor is currently responsible for developing and maintaining the emergency action plan in accordance with 29 CFR 1926, 29 CFR 1910.38 and the Emergency Management Plan (DOE 2000a).

\section{FIRE DEPARTMENT/BRIGADE}

During construction and operation, fire rescue duties are the responsibility of the operating contractor's mine rescue team. In accordance with YMP policy (Dyer 2000) no fire fighting will be conducted beyond an incipient stage. Therefore manual fire fighting can not be used to mitigate MPFL determinations. Site personnel utilizing portable fire extinguishers may perform incipient level fire fighting.

\section{RECOVERY POTENTIAL}

The ability to recover from a credible subsurface fire is considered reasonably acceptable. Physical damage to the facility and its contents will be limited to the general location of the fire's origin. The use of fire-resistant or noncombustible materials for construction and operation and the operation of the installed fire protection systems will ensure this.

Program delays, due to lack of spare parts availability, are postulated only if the fire exceeds the presently defined credible subsurface fire. None of the equipment utilized in the subsurface areas is considered unique or of special design. All equipment is standard, off-the-shelf items modified for use on the Yucca Mountain Site Characterization Project.

Unacceptable levels of environmental damage, caused by a credible fire, are postulated only if the fire protection systems fail to perform as designed.

\section{SECURITY AND SAFEGUARDS}

The ESF is an unclassified facility. There are no security considerations related to fire protection. The only security consideration is related to life safety. Access to the underground facility is controlled through the portal access controller and is available only to personnel who have completed mandatory training in hazards awareness, use of lamps, and use of self-rescuers.

\section{EFFECT OF SIGNIFICANT FIRE SAFETY DEFICENCIES ON FIRE RISK}

\subsection{INTRODUCTION}

The following fire and life safety deficiencies were identified in the previous revision of this document. Sections 15.2 through 15.8 restate those deficiencies and provides an update on their status. 


\subsection{EMERGENCY CONTROL ROOM}

"A manned surface facility is not presently designated for use as an emergency control room. Such a facility would act as the focal point and emergency coordination control center during any underground emergency. Control of the following systems should be in this control room: critical ventilation; communications; smoke detection/fire alarms; and utility and environmental monitoring.

A manned control room will reduce the possibility for confusion during subsurface emergencies, by centralizing equipment trouble alarms and controls, and by having a designated person to provide prompt response and notification to appropriate parties of status of ventilation systems, etc. The implementation and manning of this control room should be made a priority to enhance life safety in the ESF."

\subsubsection{Current Status}

This deficiency is open. A conceptual design for an integrated operations approach is in the planning stages. A design modification to the Change House to include an operational control room is contained within the current draft BSC budget. Design and construction of the operational control room is planned to be accomplished in the period from FY02 to FY04. Schedules for this work will vary depending upon funding levels and priority evaluations.

There is an Operation Center where personnel have access to all flow diagrams and circuit drawings. During an emergency, personnel can review the appropriate documents and make decisions following the emergency plan to mitigate the emergency. If a base program operations emergency (a prolonged emergency) is determined then personnel from the operations center coordinate their activities with the emergency operations team from this location. Site personnel have no means to control any operations from this room. They can direct others to perform actions, i.e., reversing the fans, to mitigate the emergency. Currently there is no one place where the control of the critical ventilation systems; communications; smoke detection/fire alarms; and utility and environmental monitoring can be monitored, or controlled or where alarms are received.

\subsection{EXIT AND EMERGENCY LIGHTING}

"Neither exit lighting nor emergency lighting is provided in the ESF Main Drift. Both are required by the ESFDR and for life safety. The current practice requiring all subsurface personnel to carry a miner's light instead of emergency lighting is an acceptable interim measure. However, the installations of both exit and emergency lighting is still a necessary requirement for life safety."

\subsubsection{Current Status}

This deficiency is open. The Title III Evaluation Report for the Subsurface Lighting System recommended that exit lighting with battery backup be installed at intersections to identify the direction of evacuation within the tunnel and alcove (CRWMS M\&O 1998g, Section 7.1.1). It also recommended that emergency lighting with battery backup be installed at $167 \mathrm{~m}$ (600 feet) intervals to light stations with telephones and fire extinguishers" (CRWMS M\&O 1998g, Section 
7.1.2). These systems are in the process of being installed with installation scheduled for completion June 3, 2002 (Broom 2001).

\subsection{FIRE ALARM, EMERGENCY NOTIFICATION SYSTEM}

"Installation throughout the ESF, of an improved paging/warning system, is a requirement for life safety."

\subsubsection{Current Status}

This deficiency is closed for the subsurface ESF. The surface portions of this system are still being installed. Emergency communication is provided by an industrial paging/warning system. To improve reliability, this system is connected to a separate dedicated cable system that is physically separated from the telephone cable system. It allows an individual to be paged, then respond and conduct a two-way conversation with the paging party. It has a siren and flashing lights to provide audio and visual signaling (CRWMS M\&O 1999b, Section 7.5.4). This system is installed so that it can be heard to warn and alert all personnel working in the alcoves or niches during an emergency (CRWMS M\&O 1998b, Section 7.5.4).

\subsection{PRE-ENGINEERED, ONBOARD, FIRE SUPPRESSION SYSTEMS}

"Diesel-powered mobile equipment (other than locomotives), and the maintenance railcar, currently used throughout the ESF for maintenance and construction, does not comply with MSHA 30 CFR 75.1911 requirements for onboard fire suppression systems. The retrofitting of all subsurface mobile equipment and the railcar with these systems, is a necessary requirement for life safety, and OSHA compliance."

\subsubsection{Current Status}

This deficiency is closed. Both the maintenance railcar and the TBM have had automatic fire suppression systems installed (CRWMS M\&O 1999a, Section 6.17). These systems can be actuated automatically through the use of a detection system or can be manually discharged by the operator.

\subsection{BUILDING FIRE-RESISTANCE}

"The office building located in alcove 4 does not comply with the OSHA 1926 requirement for one-hour fire-rated structures."

\subsubsection{Current Status}

This deficiency is closed. All components of this office building have been disassembled and removed.

\subsection{FIRE WATER SYSTEM}

"The fire water system does not comply with the requirements of NFPA 14 and contains some unlisted/non-approved components. Section 6.2 requirements are not met. 
Noted deficiencies are:

- Flexible rubber hose is used to connect fire hose stations to the non-potable water supply line.

- Non-listed water meters are proposed for installation in the supply line to each fire hose station.

- The available system residual pressure exceeds allowed level in some areas, such as alcove 5 . The system should be analyzed and pressure reducers installed at those locations where the nozzle residual pressure exceeds 6.9 bar ga (100 psi) when flowing $6.3 \mathrm{l} / \mathrm{s}(100 \mathrm{gpm})$.

- The tunnel 6" water supply line is connected together in several locations with 4 " hard rubber hose.

This system is being reviewed for adequacy in the Title III Evaluation Report."

\subsubsection{Current Status}

This deficiency is open. The piping system supplying water to the individual fire hose stations does not comply with NFPA 14 requirements. This system was installed to provide construction personnel with a source of water for construction activities. This system was not designed as a fire water supply line. For convenience, and cost savings the existing water piping was modified to install fire hose stations to provide this backup capability. Each hose station has a pressurereducing valve installed to prevent hoses from seeing pressures in excess of 100 psig (NFPA 14).

Although technically still a deficiency, it does not present a major life safety threat. The deficiency affects equipment reliability and subsequent availability. The fire hose stations are provided as backup mitigation for fighting incipient stage fires (primary mitigation is provided by portable fire extinguishers). Since it is not permitted to fight fires beyond the incipient stage, non-listed components should be adequate to support the intended use of these systems.

This system was reviewed for adequacy in the Title III Evaluation Report for the Subsurface Fire Water System and Subsurface Portion of the Non-Potable Water System and recommended the following:

- Replace all the high pressure flexible hoses with carbon steel pipe,

- Leave as-constructed main tunnel piping and utility stations as is,

- Delete availability requirements for the SFWS/SNPWS because the system does not impact personnel safety and the system is not required to function after an earthquake.

(CRWMS M\&O 1998f, Sections 7.2, 7.3, \& 7.4)

\subsection{MAN-CAR NOISE ATTENUATION}

"A need to attenuate noise levels presently incurred on the personnel transport man-cars has been identified. Since there is insufficient information available at this time to adequately review this potential hazard in this FHA, the materials ultimately selected should be reviewed for suitability for fire safety before any modifications are made. This analysis should be revised, if necessary." 


\subsubsection{Current Status}

This deficiency is closed. The attenuation of noise from the mobile equipment was to be mitigated by the installation of sound absorbing materials in the personnel transport cars. The flammability and smoke generating properties of this material was in question. Subsequent to the planned installation of this material it was determined the sound attenuation properties of this material would not reduce noise levels to an acceptable level. Therefore the installation of the materials was dropped.

\section{FIRE AND LIFE SAFETY DEFICIENCIES}

\subsection{INTRODUCTION}

The following fire and life safety issues were identified in the Fire hazards Analysis Annual Review (Williams 2001). Sections 16.2 through 16.8 restate those issues and provide an update on their status.

\subsection{EMERGENCY REFUGE STATIONS IN THE ECRB CROSS-DRIFT}

"The revised FHA will address the intended use of refuge chambers in the Cross Drift."

\subsubsection{Current Status}

The area behind the bulkhead at Station $17+63$ is designated as a potential ERS. Alcove 8 is also a designated as a potential ERS. The Onsite Emergency Management procedure, states "If an emergency condition exists that prevents employees from exiting the ECRB or smoke is entering the ECRB, Underground Personnel are to proceed to the bulkhead and associated refuge chamber at either 17+63 or Alcove 8" (LP-ESH-010-BSC, Attachment 3). "If one or both of the refuge chambers is not available, the Construction Supervisor or Lead Miner will take charge and initiate a fresh air zone. Underground Personnel are to remain in the fresh air zone until help arrives." (LP-ESH-010-BSC, Attachment 3). The steel bulkhead at Station $17+63$ is scheduled to be relocated to Station $24+00$ in October 2001.

It is recommended Procedure LP-ESH-010-BSC be revised to reflect as-built conditions and to align with 30 CFR 57.11053, Escape and Evacuation Plans.

Both ERSs have ceilings approximately $4.9 \mathrm{~m}$ (16 feet) above the floor. To aid in sealing leaks near the ceiling a ladder of sufficient height should be located in each ERS.

To ensure all site personnel who work underground on a regular basis are aware of what to do in an emergency, mandatory training to the revised procedure should be provided including annual refresher training.

\subsection{TIMBER CRIBBING IN THE MAIN DRIFT}

". . . the use of timber cribbing ground support above steel sets in isolated areas of the Main Drift, which was not discussed in the original FHA, will be addressed in the revised FHA." 
Timber cribbing is used in various sections on the Main Drift to support loose rocks (CRWMS M\&O 2000b, Figure 1). This wood cribbing is not treated with a fire retardant coating. The area where the largest portion of cribbing is used is approximately $183 \mathrm{~m}$ (600 feet) in length.

\subsubsection{Current Status}

Fire scenarios involving wood cribbing supporting loose rocks were evaluated in the System Safety Evaluation of Relative Risk Associated with the Ground Support System in the 3.01X Areas. The conclusions of this report state "These fire scenarios all had a risk designation of "Low" to "Extremely Low." To extend these fire scenarios to further include igniting the wood cribbing used in six of eight 3.01X areas would further decrease the frequency of such an event and push these risk designations to the "Extremely Low" direction." The conclusion also states "The 3.01X area design upgrades will encase the existing timber cribbing, thus eliminating the potential for a fire in the subsurface. Delaying this design upgrade until repository construction (prior to repository operation), however, will not prevent this requirement from being met. The risk of fire is with the existing design is "Extremely Low" to "Low", as discussed previously" (Gwyn 2001).

\subsection{WATER AS A BACKUP FOR INCIPIENT FIRE FIGHTING}

"The use of water as a back-up system for incipient fire fighting also needs to be re-evaluated."

Water distribution piping supplying water to fire hose stations is installed through the Main Drift and the ECRB Cross-Drift. This system was installed to support construction activities and does not meet fire code requirements. Mine Rescue personnel are trained in the proper use of fire hoses. Personnel who volunteer are trained in the use of the fire hoses and are the only site personnel allowed to use them but their use is restricted to fighting incipient stage fires. Do these limited uses of the fire hoses (low number of trained personnel and restrictions to fighting incipient stage fires) justify keeping the fire hose stations and the water distribution piping system?

\subsubsection{Current Status}

This deficiency is closed. If site personnel are in the local area when a fire occurs they can, if they feel they can extinguish the fire and escape the area in a safe manner, fight an incipient stage fire with a portable fire extinguisher (McDonald 2001). If an extinguisher cannot extinguish the incipient stage fire, personnel are to leave the immediate area and use the emergency communication system to announce a fire to all in the ESF. The fire hose stations located throughout the Main Drift and ECRB Cross-Drift are there to backup the fire extinguishers while fighting an incipient stage fire. Site personnel receive general fire hose training in Incipient Stage Fire Fighting Training (CRWMS M\&O 1997b). They are not required to use fire hoses and do not receive hands-on training of fire hoses unless they volunteer for the additional training. The mine rescue teams are trained in the proper use of fire hoses and several locomotive operators have also volunteered for the training. The operators will be the first to respond whom are trained to use the fire hoses. The mine rescue team are located a distance from the ESF with a response time of 1-2 hours upon notification. 
As described in Section 15.7, the hose system does not meet code requirements, there is a small number of trained site personnel in the use of these fire hoses and the use of the fire hoses are restricted to incipient stage fires. If personnel are not in the area when the fire is in the incipient stages the fire extinguishers and fire hoses are of little value. If personnel are in the area of the fire they can use the fire extinguishers and they can, if trained, use the fire hoses to fight the fire. The water supply piping is there to support construction operations and will not be removed. If the fire hoses are removed then personnel in the area where a fire starts have no backup unless there is another fire extinguisher available (fire extinguishers are spaced approximately every 200 feet). It is recommended that the water supply piping be upgraded (CRWMS M\&O 1998f, Section 7.2) and site personnel be given mandatory hands-on training in the use of fire hoses.

\subsection{EMERGENCY LIGHTING AND EXIT SIGNS}

"The emergency lighting and exit lights have not been installed in the subsurface. This work is currently scheduled to begin in two months."

The installation of the emergency lighting and exit sign systems, as required by Section 3.8.2.4.1C\&D of the ESFDR Criteria 6.2, have not been completed.

\subsubsection{Current Status}

This deficiency is open. See discussion in Section 15.3.1.

\subsection{VISUAL WARNING SYSTEM AND STATUS INDICATORS}

"The visual warning system and the facility control and status indicators, located in the North Portal Lamp Building, have not been completed."

The installation of the visual warning and status indicators, as required by Section 3.8.2.9.1B of the ESFDR (YMP 1997), have not been completed.

\subsubsection{Current Status}

This deficiency is open. Installation is scheduled for completion in FY02.

\subsection{SMOKE DETECTOR SYSTEM IN ALCOVE 5}

"The smoke detector system, located in Alcove 5, while providing a local alarm function, has not been connected to the control and status indicator panel. This work would be completed during construction of the visual warning system."

Upon detection of smoke the automatic detection system installed in Alcove 5, activates local audible and visual alarms so personnel can evacuate the area then it actuates the fire suppression system. Personnel on the surface are unaware of the emergency in Alcove 5 until someone uses the emergency communication system to make an announcement. A remote monitoring signal is required to be sent to an occupied location, such as an emergency control room. 


\subsubsection{Current Status}

The status of this deficiency is open. It was noted during the site visit this remote signal has not been installed but will be installed in FY02.

\subsection{WATER SUPPLY PIPING SUPPORTS}

"The water supply piping supports need to be reworked."

The water supply piping supports subsurface construction activities and supplies water to the fire hose stations. This systems, as installed, may not survive the design basis seismic event and should be upgraded with seismic restraints to meet those requirements.

\subsubsection{Current Status}

This deficiency is open. The Title III Evaluation Report for the Subsurface Fire Water System and Subsurface Portion of the Non-Potable Water System recommended the availability requirements for the SFWS/SNPWS be deleted because the system does not impact personnel safety. The system is not required to function after an earthquake (CRWMS M\&O 1998f, Section 7.3). It also recommended that seismic restraints be installed, to existing pipe support brackets to prevent detachment of the SFWS/SNPWS piping (CRWMS M\&O 1998f, Section 7.4).

\section{CONCLUSIONS}

\subsection{INTRODUCTION}

This section discusses the conclusions reached by this FHA. The conclusions are separated into the same areas as discussed in Section 9. Based on this analysis and the site visit each area will be evaluated to determine if the program objectives, required by DOE Order 420.1 , Section 4.2(1), and described in Section 1, are met. These conclusions are:

- An acceptable level of life safety is provided.

- The risk of a damaging fire occurring is very low.

- A fire will not cause an on-site or off-site release of hazardous or radiological material.

- Unacceptable interruptions to vital DOE programs are unlikely.

- Property damage from a fire will not exceed acceptable levels.

- Critical process controls and safety class systems are not applicable to the ESF construction or operation. 


\subsection{MOBILE EQUIPMENT}

The conclusion of this FHA is that the mitigating features installed on-board the mobile equipment provide an acceptable level of life safety. The risk of a damaging fire is low because of their on-board automatic fire suppression systems. Since the mobile equipment does not use hazardous or radioactive materials they will not cause either an on-site or off-site release of these materials. If a fire does occur that involves this equipment the property damage will not exceed acceptable levels. The mobile equipment does not have critical process controls and are not classified as safety class equipment.

\subsection{MAIN DRIFT}

The conclusion of this FHA is that the installed features of the Main Drift provide an acceptable level of life safety. The risk of a damaging fire is low because of the low quantity of combustible loading. No hazardous or radioactive materials are stored in the Main Drift therefore there cannot be either an on-site or off-site release of these materials. If a fire does occur in the Main Drift property damage will not exceed acceptable levels. Additional study is required to identify the extent of the problem, develop mitigating features, and to determine the impact to the Main Drift and to the site characterization schedule. The Main Drift does not have critical process controls and do not contain safety class systems, structures or components.

\subsection{ECRB CROSS DRIFT}

The conclusion of this FHA is that the installed features of the ECRB Cross-Drift provide an acceptable level of life safety upon completion of the ERSs. The risk of a damaging fire is low due to the low quantity of combustible loading. No hazardous or radioactive materials are stored in the ECRB Cross-Drift therefore there cannot be either an on-site or off-site release of these materials. If a fire does occur in the ECRB Cross-Drift property damage will not exceed acceptable levels. The ECRB Cross-Drift does not have critical process controls and do not contain safety class systems, structures or components.

\subsection{ALCOVES}

The conclusion of this FHA is that the installed features of the alcoves provide an acceptable level of life safety. The risk of a damaging fire is low due to the low quantity of combustible loading. Since the alcoves do not use hazardous or radioactive materials they will not cause either an on-site or off-site release of these materials. If a fire does occur the property damage will not exceed acceptable levels. The alcoves do not have critical process controls and do not contain safety class systems, structures or components.

\subsection{NICHES}

The conclusion of this FHA is that the installed features of the niches provide an acceptable level of life safety. The risk of a damaging fire is low due to the low quantity of combustible loading. Since the niches does not use hazardous or radioactive materials they will not cause either an onsite or off-site release of these materials. If a fire does occur the property damage will not exceed acceptable levels. The niches do not have critical process controls and do not contain safety class systems, structures or components. 


\subsection{FIRE AND LIFE SAFETY DEFICIENCIES}

The following fire and life safety deficiencies were identified in the previous revision of this document and remain open.

- Emergency Control Room. A conceptual design for an integrated operations approach is in the planning stages. A design modification to the Change House to include an Operational Control Room is contained within the current draft BSC budget. Design and construction of the Operational Control Room is planned to be accomplished in the period from FY02 to FY04. Schedules for this work will vary depending upon funding levels and priority evaluations. (Section 15.2)

- Fire Water System. The Title III Evaluation Report recommended the following:

Replace all the high-pressure flexible hoses with carbon steel pipe, Leave as-constructed main tunnel piping and utility stations as is,

Delete availability requirements for the SFWS/SNPWS because the system does not impact personnel safety and the system is not required to function after an earthquake. (Section 15.7)

The following fire and life safety deficiencies were identified in this Fire Hazards Analysis Annual Report and remain open.

- Emergency Lighting and Exit Signs. These systems are in the process of being installed with installation scheduled for completion June 3, 2002 (Section 16.5.1)

- Visual Warning System and Status Indicators. Installation is scheduled for completion in FY02. (Section 16.6.1)

- Smoke Detector System in Alcove 5. It was noted during the site visit this remote signal has not been installed but will be installed in FY02. (Section 16.7.1)

- Water Supply Piping Supports. It is recommended that seismic restraints be installed to existing pipe support brackets to prevent detachment of the SFWS/SNPWS piping. (Section 16.8.1).

- The FETD prepared to confirm the design of the ERSs calculated the carbon monoxide levels in the air. It assumed the ERS was airtight and the design basis fire was based on inaccurate information. The FETD should be revised and a system safety analysis should be performed on the design of the ERS. (Section 9.4.11.4)

\section{RECOMMENDATIONS}

The following recommendations will be entered into the Condition/Issue Identification and Reporting/Resolution System (CIRS) database and tracked to closure. Upon closure of the recommendations the FHA will be updated.

\subsection{PROCEDURE REVISION}

Procedure LP-ESH-010-BSC should be revised to reflect as-built conditions and to align with 30 CFR 57.11053, Escape and Evacuation Plans. 


\subsection{ERS}

\subsubsection{Ladder}

Both ERSs have ceilings approximately $4.9 \mathrm{~m}$ (16 feet) above the floor. To aid in sealing leaks near the ceiling a ladder of sufficient height should be located in each ERS.

\subsubsection{System Safety Analysis}

To ensure the ERSs provide a safe haven for personnel a System Safety Analysis should be performed on their design.

\subsection{TRAINING}

\subsubsection{Procedure}

To ensure all site personnel who work underground are aware of what to do in an emergency, mandatory training to revised procedure LP-ESH-010-BSC should be provided and included in annual refresher training.

\subsubsection{Lesson Plan}

Provide hands-on training for portable fire extinguishers and small fire hoses in accordance with the Incipient Stage Fire Fighting Training lesson plan (CRWMS M\&O 1997b).

\subsection{MAINTENANCE AND TESTING}

\subsubsection{Subsurface Fire Water System}

To ensure the adequacy and function of the Subsurface Fire Water System the maintenance and testing procedures should be reviewed and evaluated.

\subsubsection{Wood Rail Ties}

Due to daily wear on the wood rail ties in the ECRB Cross-Drift an evaluation should be performed to verify the contractor applied fire-retardant coating is still within the manufacturers recommendations and each exposed tie surface remains properly coated. 